Aus dem Laboratorium der Medizinischen Klinik zu Leipzig.

\title{
Beitrag zur Histologie der menschlichen Spermien und zur Lehre von der Entstehung menschlischer Doppel(miss)bildungen.
}

\author{
Von
}

Dr. P. A. Hoefer.

Hierzu Tafel II-IV.

\section{I.}

Gelegentlich der Untersuchung des Ejakulates eines 23jährigen Sexualneurasthenikers wurde ich auf atypische Formen der menschlichen Spermien aufmerksam. Einige besondere Bildungen, die ich auch im Sperma von gesunden Individuen regelmässig nachweisen konnte, und ebenso Befunde bez. der Struktur normaler Spermien, veranlassten mich dazu, meine Untersuchung weiter fortzuführen, über deren Ergebnisse ich in dieser vorläufigen Mitteilung in Kürze berichten will. Vorausschicken will ich noch, dass ich meine Untersuchung aus äusseren Gründen abschliessen musste, noch bevor es mir möglich war, die Literatur über atypische Spermien eingehender durchzusehen, sodass ich einige Punkte nur kurz gestreift habe, die ich sonst ausführlicher untersucht haben würde.

Die Literatur über atypische Spermien ist ausführlich von Broman $(10,11)$ und Retzius $(27)$ zusammengestellt und besprochen worden. Ausserdem verweise ich noch auf das von Waldeyer bearbeitete Kapitel über „Die Geschlechtszellen in 0 . Hertwigs Handbuche der vergleichenden und experimentellen Entwicklungslehre der Wirbeltiere (35). Ich darf mich deshalb bei der Besprechung der Literatur kurz fassen, und brauche nur auf die letzten Arbeiten von Broman und Retzius näher einzugehen.

Broman $(10,11)$ unterscheidet beim Menschen vier Hauptformen der atypischen Spermien: 
a) Spermien, die nur durch die Grösse von den anderen normalen, differieren: Riesen- und $Z$ wergspermien.

b) Spermien mit einfachem Kopfe aber zwei oder mehr Schwänzen.

c) Spermien mit zwei oder mehr Köpfen, die ein- oder mehrschwănzig sein können.

d) Spermien, die einfach und normal gross sind und nur durch abnorme Form abweichen.

Die mehrschwänzigen und -köpfigen Spermien entwickeln sich nach Broman aus Spermatiden, die durch anormal verlaufende Mitosen entstanden sind. Bilder, die diese Annabme beweisen kiönnten, sah er an Hodenschnitten. Im Anschluss an Bromans Arbeiten hat dann Retzius (27) alte und neue eigene Beobachtungen veröffentlicht. Nach seiner Meinung entstehen die zweischwänzigen Spermien durch Teilung des Achsenfadens; wenigstens in der Regel. Doch will er Bromans Ansicht nicht unbedingt abweisen, wenn sie auch nicht hinreiche, das so zahlreiche Vorkommen nur teilweise gespaltener "Doppelschwänze" zu erklaren. Nach Broman und Retzius haben noch andere Autoren atypische Spermien bei verschiedenen Tieren nachgewiesen, z. B. Schminke (30) unter den Ruminantierspermien. Formen mit mehr als zwei Köpfen resp. Schwänzen konnte er aber nie sehen.

Von den Angaben bez. des färberischen Verhaltens der Spermien führe ich nur die mir am wichtigsten erscheinenden an und verweise im übrigen auf $\mathrm{W}$ aldeyers Darstellung. Ballowitz (2-4), Barde leben (7) und andere Autoren haben bei Säugetierspermien das verschiedene Verbalten des vorderen und hinteren Kopfabschnittes Farbstoffen gegenüber bez der Intensität der Färbung, und die Refraktionsunterschiede zwischen beiden Abschnitten hervorgehoben. Pappenheim (23) gelang der Nachweis, dass bei menschlichen Spermien der hintere, stärker lichtbrechende Abschnitt des Kopfes andere Färbung annehmen kann als der vordere. Er erhieit bei Anwendung der Nochtschen Modifikation der Romanowsky-Färbung folgende Resultate: das Mittelstück des Spermium färbte sich rein dunkelblau, das Endstück des Schwanzes eher blau als rosa. Am Kopfe erscheint der dem Geisselschwanze unmittelbar knospenförmig aufsitzende basale Binnenkegel rot mit einem leichten Stich ins Archiv f. mikrosk. Anat. Bd. 74. 
Violette, die restierenden Teile des Kopfes in reinem Mattblau. Bei Anwendung des Methylgrün-Pyroningemisches färbte sich das Köpfchen in toto grün, nur erschien der Innenkegel dunkler, die Kappe matter; das Mittelstück leuchtend rot, der Rest der Schwanzgeissel blieb ungefärbt. "Irgendwie weittragende Folgerungen daraus ziehen $z u$ wollen" lehnte er aber ab. Eine andere Differenzierung am Spermienkopfe bei Wirbeltieren fanden Grobe (13), später Miescher (22) und Jensen (16): sie unterschieden eine hellere Aussenschicht von einer dunkleren Binnenmasse (Färbungen mit Säurefuchsin und Goldchlorid).

Ich untersuchte die Spermien ausser im lebenden Zustande - ev. noch unter Zusatz von Azur II -, hauptsächlich an verschieden gefärbten Ausstrichpräparaten. Für die Durchsicht meiner ersten Präparate bin ich Herrn Geh.-Rat Marchand zu Danke verpflichtet.

Zur Färbung benutzte ich zunächst Jenners Farbstoff, dann zum Vergleiche noch $L$ e is h manns und $M$ ay-Grünwalds Farbstoff, Giemsas Lösung für Romanowsky-Färbungen, Ehrlichs Triacid, Eosin-Hämatoxylin, Methylgrün-Pyronin (Pappenheim) und Methylblau-Eosin (Mann). Mittels einiger von diesen Methoden ist es mir gelungen, einige bisher nicht bekannte Strukturverhältnisse bei normalen und atypischen menschlichen Spermien nachzuweisen. Die besten Resultate erhielt ich bisher bei Anwendung der Jennerschen Flüssigkeit, und auf Färbung mit dieser beziehen sich die weiteren Angaben, falls nicht ausdrücklich andere Färbemethoden angegeben sind ${ }^{1}$ ).

Ich beschreibe zunächst meine Befunde bei den normalen Spermien.

\section{Der Kopf.}

Schon in meinen ersten Präparaten fiel es mir auf, dass sich ein hinterer, mittlerer Kopfabschnitt bläulich färbte - entsprechend den Leucocytenkernen - , während der vordere Teil und schmale seitliche Streifen des Kopfes eine mehr rosa Färbung annahmen. Durch Modifikation der Jennerschen Färbung nach Zeitdauer, Wasserzusatz etc. gelang es mir im Spermiumkopf einen Körper nachzuweisen, der sich durch scharfe Konturen und

1) Anm. währ. d. Korr.: Inzwischen habe ich auch nach Giemsa recht gute Resultate erhalten (s. unten). 
seine distinkte Färbbarkeit von der umgebenden Substanz des Kopfes scharf absetzte. Ich will im folgenden - gestützt auf noch andere, weiter unten $\mathrm{zu}$ erwähnende Befunde - diesen Innenkörper als den „Kern“ im Spermiumkopfe bezeichnen, obgleich die Ergebnisse der Metbylblau-Eosin-, und Methylgrün-PyroninFärbung (siehe unten) auch noch eine andere Deutung zulassen.

Der "Kern" erschien bei dieser Färbung zart hellblau, meistens homogen, ohne Andeutung einer weiteren Innenstruktur. Doch sah ich bisweilen in oder auf ihm noch weitere Einzelheiten. So (Fig. 47 und 48) einen ihn gürtelförmig umgebenden Kranz von 5-8 feinsten, dunkelblau-violett gefärbten Körnchen ${ }^{1}$ ). Diese umgeben ihn an seinem "Äquator“, oder noch etwas mehr nacb dem vorderen Kernpole zu, jedenfalls immer in gleicher Anordnung und in derselben Richtung, nämlich senkrecht zur Längsachse des Spermium. Es war mir noch nicht möglich, sicher festzustellen, ob sie randständig im Kerne selbst liegen oder aber ihm nur aufgelagert sind. Jedenfalls dürften sie in Anbetracht ihres konstanten Verhaltens nicht ohne Bedeutung sein. Sie decken sich nicht mit den bisher beschriebenen körnchenförmigen Einlagerungen im Spermiumkopfe. Bei Färbungen mit Methylblau$\operatorname{Eosin}(\mathrm{Mann}$ ) sind sie leichter darstellbar (s. unten). (Die Körnchen färben sich nach Giemsa (s. unten) leuchtend rot bis rot-violett: gehören also zur chromatischen Substanz der Zelle. Auch der Bewegungsapparat der Trypanosomen färbt sich leuchtend rot nach Giemsa. Die Körnchen könnten also, falls sie nicht zum Kerne selbst gehören (Nukleolen?) oder zu Vorgängen im Kerne in Beziehung stehen (Chromosomen?), atch zum Bewegungsapparat des Spermium gehören. $)^{2}$ ) Einmal sah ich dabei eine deutliche streifige Struktur des „Kernes" (Fig. 47), einigemale auch nur zwei, ebenso gefärbte, aber etwas grössere Körnchen (Fig. 49); oder auch zwei unscharf umrissene, etwas dunkler als der "Kern" gefärbte Gebilde (Fig.50).

Der „Kern" zeigt nach Lage, Form und Grösse ein wechselndes Verhalten. Meist liegt er im hinteren Kopfabschnitt der stark lichtbrechende "Innenkegel" der lebenden Spermien. Während er nach dem Halse zu fast stets abgerundete Konturen

1) Die genaue Zahl, und ob diese konstant ist, konnte ich bisher noch nicht feststellen.

2) Anmerkung während der Korrektur. 
zeigt - seltener läuft er spitz nach hinten aus -, weist sein vorderer Pol öfters einen flachen herzförmigen Einschnitt auf (Fig. 4). Bisweilen ist der vordere Rand gezackt und geflammt (Fig. 6, 8, 9), was vielleicht auf einen Kernzerfall bindeutet, sich aber vielleicht auch so erklären lässt, dass der Kern, wenn er nach vorn $\mathrm{zu}$ - entsprechend der normalen Kopfform - in eine spitzere Schneide ausläuft, dabei an verschiedenen Stellen verschieden schnell an Dicke abnimmt. Jedenfalls sieht man zwischen diesen Zacken eine bläulichere Färbung und nicht die übliche rosa Färbung der Wandschicht "des Protoplasmas". Andere Formen des Kernes - Birn- oder Mandelform - zeigen die Fig. 2, 3, う, 7 etc. Sehr häufig ist der Kern so gross, dass er allein den Kopf darzustellen scheint, und nur noch ein ganz schmaler Protoplasmasaum übrig bleibt. Dies findet man besonders bei den Spermien mit gut erhaltener Birnform des Kopfes (bei Seitenansicht), die sich auch bei Fărbungen mit MethylgrünPyronin fast in toto gleichmässig dunkelgrün färben.

Es liesse sich nun einwenden, dass die Unterschiede in der Färbbarkeit der verschiedenen Kopfteile auch schon durch Dickenoder sonstige Unterschiede innerhalb einer gleichartigen, den Kopf darstellenden Substanz bedingt sein könnten. Dass dies nicht der Fall ist, sondern dass es sich um einen gesonderten Innenkörper im Spermienkopf handelt, den ich unter Vorbehalt als "Kern" bezeichne, beweisen, abgesehen von der charakteristischen Färbung und scharf umrissenen Form, besonders auch Bilder, wie sie in Fig. 43 und 44 dargestellt sind. Fig. 44 zeigt einen Kopf, dessen vorderer Pol heim Ausstrich abgequetscht worden ist und man sieht nun, wie die beiden langlichovalen Kerne (auf die Bedeutung der Duplizită komme ich unten zu sprechen) mit ihren Spitzen eben aus dem Protoplasmaleib des Kopfes hervorragen. Noch deutlicher wird es in Fig. 43, wo offenbar ebenfalls durch Druck bei der Präparation der Kern aus dem Kopfe zum grössten Teile herausgepresst worden ist. In seinen vordersten Partien ist der Kern etwas beschädigt und zeigt keine scharfen Konturen; der geringeren Dichte entspricht hier eine blassere Färbung. Im Kopfe zeigen einige hellere Stellen den Platz an, den die Masse des Kernes bisher ausfüllte. Am hinteren Kernpole sieht man einige rötliche Granula auf dem Kerne liegen. Diese Tatsache, dass aus dem Spermiumkopfe dieser Körper 
isoliert auszutreten vermag, veranlasst mich dazu, hier von einem "Kerne" zu reden.')

Neben diesen Spermien mit einem sich bläulich färbenden Kerne findet man aber hin und wieder auch solche, die ein anderes färberisches Verhalten zeigen. Bei ihnen färbt sich ein unscharf begrenzter Innenkörper oder auch der ganze hintere Kopfabschnitt leuchtend rot, bisweilen mit einem Stich ins Violett. Der hintere Kopfabschnitt setzt sich manchmal mit einem nach vorne zu konkaven Rande gegen den vorderen, zart rosa gefärbten Kopfabschnitt ab, sodass sich eine Eichelform des Kopfes ergibt. Andere Erscheinungen am Spermium, die einen sicheren Schluss auf degenerative Vorgänge in ihm zuliessen, konnte ich dabei nicht finden. Doch möchte ich glauben, dass es sich hier um "überreife" Spermien handelt, die sich einem Degenerationsstadium nähern, und in deren Kernsubstanz chemische Umsetzungen vor sich gegangen sind. Entsprechende Befunde ergaben sich auch, wenn andere Färbungen angewendet wurden So nahmen bei Methylgrün-Pyronin-Farbung immer einzelne Spermien das Pyronin an und nicht, wie die überwiegende Mehrzahl, das Methylgrün. Bei Anwendung des Methylblau-Eosin (Mann), wo sich der Regel nach der Kern l'ot farbt, zeigten immer einige Kerne grössere Affinität zum Methylblau (s. unten). Bei diesen abweichenden Formen waren die Kerngrenzen meist unscharf, das Gefüge des Kernes scheinbar lockerer, weniger dicht als üblich. Daneben gibt es aber auch noch Übergangsformen zwischen beiden Arten, die bei der II annschen Färbung besonders leicht aufzufinden sind, bei denen der Kern in einem bläulichen Rot erscheint, die BlauComponente sich verschieden stark geltend macht. Die Zahl der so abweichenden Spermien ist eine wechselnde. Sollte es sich um ältere, degenerierende Formen handeln, so wäre die Erklärung dafür leicht zu geben. Immerhin wäre aber auch an die Befunde von Auerbach (1) bez. der Erythrophilie und Cyanophilie der Eikerne bez. der Spermienköpfe zu erinnern (vergl. dazu Pappenheims Ausführungen [23]) und an den

1) Denn durch diese Befunde (s. auch unter: "Mehrkernigen Spermien") wird der "Kern" nicht nur durch sein färberisches, sondern auch durch sein morphologisches Verhalten als Kern charakterisiert. 
von verschiedenen Autoren angenommenen Dimorphismus der Spermien (Bardeleben, Beard [8]).

Die den Kern umgebende Substanz des Kopfes nimmt bei Farbung mit Jenner eine blassere oder intensivere rosa Farbe an. Sie macht meist einen homogenen Eindruck, doch sieht man auch hin und wieder in jhr feinere oder gröbere Granula von gleicher Tinktion.

Färbung mit Metbylblau-Eosin (Nann): Nach Mann (17) wird bei dieser Färbung in den Nervenzellen das Chromatin des Kernes tiefblau gefärbt, die Nukleolen rot oder violett. Ich erbielt bei ibrer Anwendung (lange färben!) im blassblau gefärbten Spermienkopfe einen leuchtend rot gefürbten Innenkörper von ähnlicher Färbung, wie die dem Präparate experimenti causa beigefügten Erythrocyten. Die Schwanzgeissel war rötlichviolett tingiert, die Kerne der Lymphocyten und Leucocyten intensiv blau, die eosinophilen Leucocytengranula leuchtend rot innerhalb eines bläulichen Maschenwerkes, das Plasma der Leucocyten zum Teil zart bläulich. Der rote Innenkörper weist starke Schwankungen der Grösse nach auf; bisweilen füllt er fast den ganzen Kopf aus, und dies scheint mir, abgesehen von anderen Momenten, gegen die Auffassung zu sprechen, dass es sich hier um einen Nukleolus handele. Auch hinsichtlich der Farbennuance finden sich starke Unterschiede, vom leuchtenden Eosinrot bis zu einem matten Violett. Bisweilen scheinen sich Schichten einer bläulich gefärbten Substanz um einen roten Kern zu lagern. (Vergl. das oben über färberisch abweichende Formen gesagte.) Die den Kern kranzartig umgebenden Körnchen (s. oben) lassen sich manchmal auch mit der stärksten Vergrösserung nur mit Mühe als distinkte, feinste Körnchen unterscheiden: ihre Gesamtheit imponiert dann als eine feine dunkelblaue Linie - vielleicht dieselbe, die an lebenden Spermien bisweilen als Grenze der Kopfkappe erscheint. (Anm. währ. d. Korrektur: Die Färbang $\mathrm{nach}$ Giemsa liefert folgendes Ergebnis: Ausser selteneren, degenerierenden Formen, deren Köpfchen sich in toto rosa fărbt, findet man 1. einmal Bilder wie bei der Färbung nach Jenner, nämlich einen bläulichen Kern mit schmalem oder breiterem, rosa Protoplasmasaum [entsprechend etwa Fig. 58 oder 66]. Hier sieht man häufig einen Kranz von feinen, roten bis violetten Körnchen den Kern umgeben [s. d. Anm. oben auf S. 35]. Sie sind nicht 
immer rund sondern bisweilen länglich, stäbchenförmig. Nur einmal schienen sie mir schleifenförmig geknickt zu sein. Daneben sieht man aber, ebenso häufig wie die unter 1 . beschriebenen Formen, 2. Spermien, deren Kopf in toto eine rot-violette Färbung angenommen bat, und zwar entweder im hinteren Kopfabschnitte intensiver als im vorderen oder gleichmässig im ganzen Köpfchen. $\mathrm{Ob}$ auch hier der Ring von feinen Körnchen nachweisbar ist, kann ich zurzeit noch nicht mit Sicherheit angeben. Bei diesen Formen erscheint der Kopf nicht homogen, sondern man bat eher den Eindruck eines lockeren Gefüges resp. Knäuels der sich rotviolett färbenden Substanz. Nur einmal hatte ich bisher folgenden Befund: Die chromatische Substanz war an den beiden Polen des Kopfes in etwa gleichgrosser Menge als zwei rot-violett gefärbte Knäuel angehäuft, zwischen denen ein blassblauer Streifen in einer Breite von etwa einem Fünftel des Lăngendurchmessers des Kopfes freigeblieben war. Ein rosa gefärbter Plasmasaum war nicht zu bemerken.)

Farbung mit Methylgrün-Pyronin: Diese gibt wieder andere Resultate: Der hintere Kopfabschnitt ist dunkelgrün gefärbt, der vordere entweder ganz zart hellgrün bis farblos, oder mit einer zart rosa Nuancierung. Selten umgibt ein roter Saum den Kopf. Verbindungs- und Hauptstück erscheinen zart rosa gefärbt, fast farblos - ein Randsaum ist intensiver rot; bisweilen erhielt ich aber auch die Schwanzgeissel deutlicher rosa. Der Kranz feiner Körnchen um den Kern wird nicht gefärbt, statt dessen finden sich bisweilen in gleicher Anordnung eine Reihe von etwas heller grün erscheinenden, entsprechend grossen Stellchen ("Vakuolen“?). Den vorderen Kopfabschnitt sah ich einige Male von dunkelgrünen, von der Grenze $z$ wischen vorderem und hinterem Kopfabschnitt ausgehenden, nach vorne zu divergierenden Strahlen durchzogen wohl Produkte der beim Trocknen des Präparates entstehenden Schrumpfung. Wie schon oben erwähnt, finden sich auch hier abweichende Formen, deren Kopf sich mit Pyronin intensiv rot färbt. Färbt man ausserdem noch mit Eosin nach, so nimmt der vordere Kopfabschnitt meist noch eine deutliche rosa Färbung an. Doch erhält man sehr oft auch schon bei MethylgrünPyroninfärbung eine deutlich andere Farbnuance im vorderen Kopfabschnitt. 


\section{Zentrosomen.}

Hinsichtlich der Lage der Zentralkörperkörner im Halse und der Lage zueinander konnte ich ebensowenig wie hinsichtlich ihrer Zahl ein konstantes Verhalten wahrnebmen. Die proximalen fand ich zum Teil dem Kerne dicht angelagert oder seitlich von ihm, oder sie lagen an der Grenze zwischen Kopf und Hals oder auch im Halse selbst. Öfter sah ich nur ein einfaches proximales Zentrosom, das allerdings bisweilen grösser war als gewöhnlich. Waren zwei Zentralkörperkörner vorbanden, so lagen sie nicht immer seitlich neben-, sondern bisweilen auch hintereinander (Fig. §2, 55); sie waren dann auch nicht immer gleich gross, sondern das eine, das vordere oder das hintere, war grösser als das andere. Auch sah ich öfter drei vordere Zentrosomkörner, z. B. am hinteren Kernpole (Fig. 64, 65) oder auch am binteren Kopfende (Fig. 66, 67) in einer Kreislinie angeordnet liegen, zum Teil untereinander durch Fäden verbunden. Ebenso sah ich vier vordere Zentrosomkörner in einem normalen Spermium. das keine anderen Zeichen von Veränderung aufwies, und zwar je zwei links und rechts seitlich am hinteren Kernpole (Fig. 54). Hier waren die Körnchen ziemlich klein, hatten keine runde, sondern länglich ovale Form, und lagen sehr dicht, aber doch deutlich getrennt, nebeneinander. Sie waren anscheinend aus einer Teilung hervorgegangen. Ebenso glaube ich Fig. 56 deuten zu dürfen. Hier lag das eine Paar der vorderen Zentrosomkörner noch nahe beieinander, während von dem anderen Paare das distalere Körnchen schon weiter nach dem Verbindungsstück zu hinabgerückt war. Fig. 63 zeigt das einfache proximale Zentrosom mit zwei hinteren Zentrosomkörnern ( $=$ proximales Stück des hinteren Zentrosoms) in Verbindung. Ebenso sah ich auch am Ende des Verbindungsstückes ein oder zwei Körner ( $=$ distales Stück des hinteren Zentrosoms). Es können also sowohl das vordere als auch das proximale und distale Stück des hinteren Zentrosoms einfach oder mehrfach vorhanden sein und - wenigstens das vordere Zentrosom - verschiedene Lage haben.

Verbindungsfäden zwischen den Zentrosomkörnern waren nicht immer mit gefärbt. Solche Fãden sind bei Tieren schon mehrfach beobachtet und verschieden erklart worden. Eimer und Ballowitz (zitiert nach Waldeyer) nahmen an, dass der Hals stets vom Achsenfaden durchsetzt sei, der sich oft mit einem 
deutlichen Endknöpfchen versehen, am hinteren Kopfpole inseriere. Ballowitz konnte bei verschiedenen Säugetieren doppelte und dreifache Fäden nachweisen und hielt diese für die von ihm gefundenen Fibrillen des Achsenfadens Jensen dagegen bestritt, dass bei anderen Säugern, z. B. Ratte, solche Fäden im Halse nachzuweisen seien. Meves endlich konnte zeigen, dass, wenn Fäden vorbanden waren, sie die einzelnen Zentrosomstücke miteinander verbanden. Er erklärt sie deshalb für eine Bildung sui generis. Waldeyer schliesst sich seiner Deutung an und nennt sie Zentrosomtäden. Beim Menschen haben sie Broman und Retzius erwähnt, doch geben die bisher vorliegenden Abbildungen keinen sicheren Aufschluss über ihr Verbalten. Ich gehe deshalb aqusführlicher darauf ein.

Ich sah diese Zentrosomfäden meist von deutlich gefärbten vorderen Zentrosomkörnern ausgehen (Fig. 51, 52, 63, 64 etc.), doch war das an ihrem Ausgangspunkte am Kern oder an der Kopfgrenze $z u$ vermutende Zentrosom nicht immer mitgefärbt (Fig. 53, 60). ${ }^{1}$ ) Bisweilen liess sich auch der eine Faden nicht soweit bis zum Kopfe hinauf verfolgen wie die andern und schien plötzlich mitten im Halse zu endigen (Fig. 62), oder ein Zentrosomkörnchen stand nicht mit Zentrosomfäden in Verbindung. Dies findet seine Erklärung in Mängeln der Farbung etc., spricht aber nicht gegen einen engeren Zusammenhang zwischen den Zentrosomen und den Zentrosomfäden. Die Zentrosomfäden verbanden in einer gerade oder gebogen verlaufenden Linie die proximalen Zentralkörperkörner untereinander; sie verbanden andererseits auch die Körner des vorderen Zentrosoms mit den proximalen des hinteren Zentrosoms. Doch endigten die Făden nicht immer hier, sondern führten eventuell noch weiter bis $z u$ Körnern, die am Ende des Verbindungsstückes lagen, also bis zum "distalen Abschnitt des hinteren Zentrosoms". Ja, ich sah sie bisweilen noch darüber hinaus bis in das Hauptstück hinein verlaufen (Fig. 61). Ebenso waren bisweilen die vorderen Zentrosomkörner direkt mit dem distalen Abschnitte des hinteren Zentrosoms verbunden, ohne dass ein vorderer Abschnitt des hinteren Zentrosoms mitgefärbt war. Und schliesslich konnten die Fäden vom

1) Man beachtedas Verhalten des Zentrosomfadensin Fig.11, der noch ein Stück über das vordere Zentrosom hinaus nach dem Kerne zu verläuft! 
vorderen Zentrosom direkt ohne Zwischenschaltung von hinteren Zentrosomabschnitten bis in das Hauptstïck verfolgt werden (Fig. 64). Die Făden verliefen nicht immer geradlinig, sondern auch geschlängelt (Fig. 50, 53,64) oder parallel den geschwungenen Konturen des Halses und Verbindungsstückes. Oft konnte man die Fäden getrennt bis in das Hauptstück verfolgen (Fig. 61), oder bei zweischwänzigen Spermien je einen Faden in jeden Schwanz hineinlaufen sehen (Fig. 63). Anderen Teiles aber sah man sie zur Vereinigung kommen (Fig. 64), etwa im Verbindungsstück, und dann als einen Faden zum distalen Abschnitt des binteren Zentrosoms ziehen (Fig. 67) oder aber sie vereinigten sich erst dort (Fig. 65, 66). In Fig. 52 sieht man von den zwei hinteręinander gelegenen vorderen Zentrosomkörnern nur einen Faden abgehen. Meist sind es sehr zarte Fäden, doch sieht man sie öfter auch unscharf, verschwommen gefärbt, so dass die Körnchen wie in einem Bande eingebettet liegen (Fig. 65). Bisweilen hat man auch den Eindruck, als ob feine Körnchen in den Verlauf der Fåden eingestreut wären (Fig. 61); oder der Faden besteht direkt nur aus einer Reihe feiner Körnchen (Fig. 58-60). Im letzteren Falle kann, bei einer seitlichen Lage des Fadens, leicht die Meinung hervorgerufen werden, als handle es sich um eine Reihe von Spiralfadendurchschnitten (Fig. 58, 59,41 ; vgl. dagegen Fig. 60, 42) oder als gehe der Faden in den Spiralfaden über, d. h. dass das Zentrosom mit einem Spiralfaden in Verbindung stünde. Ich will mich eines Urteils über die Bedeutung dieser Făden und ibre Bezielinung zum Achsenfaden, resp. zu dessen Fibrillen, enthalten. Doch will ich nochmals darauf hinweisen, dass ich sie vom vorderen Zentrosom direkt bis in das Hauptstück verlaufen sah, und dass anderenfalls, wenn noch die Körner des hinteren Zentrosoms in den Verlauf eingeschaltet waren, kein wesentlicher Unterschied zwischen den Teilen des Fadens im Hals, Verbindungs- und Hauptstück zu bestehen schien. Bisweilen waren die Fåden im Hauptstück bedeutend feiner als im Verbindungsstück. Überhaupt schien mir der Faden immer nach dem Hauptstück zu feiner zu werden.

Bei den atypischen Spermien konnte ich ein gerade für sie charakteristisches Verhalten der Zentrosomen nicht nachweisen. Leider waren gerade bei ihnen die Zentrosomen hăufig nicht 
distinkt gefärbt, sondern es war nur eine diffuse bläulich-violette Verfärbung von Hals und Verbindungsstück eingetreten.

Ähnliche Befunde bezüglich der Zentrosomen und Zentrosomfäden erhielt ich auch bei der Untersuchung von lebenden Spermien nach Zusatz von Azur II. In Fig. 40 und 41 sieht man zwei Zentrosomkörner am Anfang des Verbindungsstückes; in Fig. 41 auch einen „Schlussring" am Ende des Verbindungsstückes und seitlich am Verbindungsstück eine fein punktierte Linie, von der hier am ungefärbten Präparat schwer zu sagen ist, wie sie aufgefasst werden muss. In Fig. 42 liegen die Zentrosomen an der KopfHalsgrenze, ein Hals ist nicht deutlich zu sehen; von den Zentrosomen gehen Fäden aus, von denen der eine, bevor er ganz aufhört, in eine Reihe feiner Körnchen zu zerfallen scheint.

Achsenfaden.

Während aus den eben angegebenen Befunden ein näherer Zusammenhang zwischen Zentrosomen, Zentrosomfäden und Achsenfaden hervorzugehen schien, sah ich an anderen Präparaten - allerdings nur in wenigen Fällen - im Verbindungs- und im Anfangsteile des Hauptstückes einen feinen, hellblaugefärbten, zentralen Faden, der sich bis zum Kerne verfolgen liess, von dem man ihn gut abgrenzen konnte. Einmal schien er mir direkt mit dem Kerne in Zusammenhang zu stehen - das Bild erinnerte an das in Fig. 54 abgebildete, wo ein Ausläufer des Kernes sich in das Verbindungsstück hineinzieht. Einmal konnte ich diesen zentralen Faden noch ein wenig bis unter den Kern verfolgen. Meine Beobachtungen sind nicht zahlreich genug, um irgend welche Schlüsse hieran knüpfen zu können. Jedenfalls stehen diese Befunde wohl nicht in Widerspruch zu den Ergebnissen der histogenetischen Untersuchungen über den Ursprung des Achsenfadens.

Verbindungsstü ck.

Eine Spiralhülle war in meinen Präparaten mit Sicherheit nicht nachzuweisen. Das Verbindungsstück war häufig stark vergrössert und verbreitert. Das Halsstück in den gefärbten Präparaten nicht so gut nachweisbar als bei frischen Spermien.

\section{Atypische Spermien.}

Auf den Bau der atypischen Spermien brauche ich im einzelnen nicht näher einzugehen, da meine Befunde im wesent- 
lichen nicht von den von Broman und Retzius beschriebenen abweichen. Ich werde deshalb nur einige Besonderheiten hervorheben, die ich noch nicht erwahnt gefunden habe.

Alle Arten der atypischen Spermien fand ich in meinen Präparaten relativ häufig. Allerdings bestanden auch ziemlich grosse individuelle Schwankungen Spermien mit mehr als zwei Köpfen konnte ich nicht finden; solche mit drei und vier Schwänzen konnte ich aber öfter sehen. Doch waren dies immer zweischwänzige Spermien, bei denen sich der eine oder beide Schwanzfäden noch einmal bis zum Verbindungsstück gespalten liatten. Dass drei oder mehr Schwảnze direkt vom Kopfe abgingen, oder dass mehr als zwei Verbindungsstücke vorhanden waren, konnte ich nie konstatieren. Bei mehrschwänzigen Spermien fand ich die Zentrosomen nicht entsprechend vermehrt. Zwischen normalen Spermien, Zwergspermien und Riesenspermien findet man die verschiedensten Übergangsformen und Grössenstufen. Fast alle die von mir beobachteten atypischen Formen bewegten sich langsamer als die normalen.

\section{Z wergspermien.}

Die kleinsten Formen der "Zwergspermien" (Broman) scheinen mir mit der von Bardeleben beschriebenen Nebenform der menschlichen Spermien identisch zu sein. Bei einer Färbung mit Hamatoxylin-Eosin fand er die Köpfchen der „Nebenform" rosa, die der Hauptform blauviolett gefärbt. Auch bei der von mir angewendeten Färbemethode nahm der Kopf der kleinsten Formen fast immer in toto eine blasse rosa Färbung an, und es gelang mir nicht, einen Kern in ihnen nachzuweisen. Hierauf beruhen wohl die Unterschiede in der Farbung. Ich habe sie deshalb zuerst, bevor ich Bromans Ansicht über die Entstehung der atypischen Spermien kannte, als degenerierte Formen aufgefasst, besonders auch deshalb, weil mir die Konturen des Kopfes meist nicht glatt erschienen, und man den Eindruck hatte, als ob der Kopf geschrumpft wäre. Daneben gibt es aber auch Zwergspermien, in denen sich ein Kern nachweisen lässt. Bilder von deutlichem Kernzerfall habe ich bei ihnen nicht gefunden. Dass es sich bei solchen, die keine Spuren von Degeneration zeigen, um atypische Bildungen handelt, scheint mir nicht ausgeschlossen. Sie würden dann ein Gegenstück 
bilden zu den von Meves (19) bei Pygăra gefundenen oligound apyrenen Spermien Der Kopf hat im allgemeinen die normale Form, auch Verbindungsstück und Hauptstück zeigen meist keine Abweichungen.

Einfache Riesenspermien.

Das auffallendste an ihnen ist die Grösse des Kopfes, der mehr als dreimal so gross sein kann als normal. Diese grössten Formen sieht man aber nur seltener, häufiger dagegen solche mit weniger stark vergrössertem Kopfe. Der Kern ist fast immer erheblich vergrössert, kann fast den ganzen Kopf ausfüllen, so dass nur ein schmaler Protoplasmasaum ïbrig bleibt. Das Verbindungsstück ist fast immer dicker als normal, meist fast doppelt so dick. Der Schwanz hat zwar im allgemeinen die normale Länge, erscheint aber ebenfalls fast immer verdickt. Dies ist bisweilen so auffallend, dass man glaubt, zwei eng zusammenliegende Schwänze vor sich zu haben. Doch lässt es sich an gut gefärbten Präparaten leicht nachweisen, dass dies nicht der Fall ist. Dagegen findet man bisweilen das letzte Ende des Schwanzes aufgespalten, ja man kann den Beginn der Spaltung auch mitten im Hauptstück eintreten sehen (Fig. 23), während dies sonst noch ungeteilt geblieben ist.

Ich halte diese Formen für Übergangsformen von den einschwănzigen Riesenspermien zu den zweischwänzigen.

Zweischwänzige Spermien.

Über zweischwänzige Spermien liegen ebenfalls ausführliche Beschreibungen besonders von Broman und Retzius vor. Der Kopf dieser Formen ist sehr häufig grösser als normal. Ausser den "Doppelschwänzen" (Retzius), bei denen sich entweder nur das Hauptstück oder Hauptstück und Verbindungsstück verdoppelt findet, sah ich auch solche, bei denen noch keine völlige, sondern nur eine auf bestimmte Strecken beschränkte Teilung eingetreten war (vergl. auch das oben über die Riesenspermien gesagte). Solche Befunde beschreibt auch Retzi us bei normalen Spermien. Er zog daraus den Schluss, dass die Doppelschwänze wohl aus solchen Spermien hervorgingen, bei denen die Aufspaltung des Achsenfadens bis zum Ende fortgeschritten sei; ohne aber die Ansicht $\mathrm{Br}$ om ans über die Entstehung zweischwänziger Spermien 
gänzlich abweisen zu wollen. In meinen Präparaten sab ich ausser Bildern, wie sie Retzius beschreibt, auch solche, bei denen sich eine beginnende $Z$ weiteilung nicht am oberen Ende des Hauptstückes, sondern auch in der Mitte oder am Endstücke nachweisen liess. Diese beginnende $Z$ weiteilung fand sich ebenso auch bei den einschwänzigen doppelköpfigen Spermien, seltener bei Spermien, die man nach Form und Grösse des Kopfes den normalen zuzählen musste.

Da es sich also zeigte, dass dieser Aufspaltungsprozess von kleinsten Anfängen bis $\mathrm{zu}$ verschiedenen Graden weit fortschreiten kann und sich fast immer nur bei Spermien findet, die sich nach Form und Grösse des Kopfes von den normalen unterscheiden, und deren Schwanz dicker ist als der der normalen Spermien oder die Schwänze der völlig ausgebildeten Doppelschwănze, so lag der Schluss nahe, dass es sich bei allen diesen Formen nur um Glieder einer Kette, um verschiedene Entwicklungsstufen ein und desselben Prozesses handele.

\section{Zweiköpfige Spermien.}

Nun konnte ich aber auch unter den zweiköpfigen Spermien Bildungen nachweisen, die man wohl mit den bei den Doppelschwänzen beobachteten Formen, die als verschiedene Stadien eines Zweiteilungsprozesses erscheinen, in Parallele setzen darf.

Die beiden Köpfe unterscheiden sich nicht wesentlich von den Köpfen der normalen Spermien, weder nach Form und Grösse, noch nach Beschaffenheit des Kernes und Protoplasmas. Ihre Längsachsen laufen nicht parallel, sondern schliessen einen spitzen bis stumpfen Winkel ein. Meist sind beide Köpfe annähernd gleich gross, selten ist einer grösser als der andere; in letzterem Falle besteht dann meist auch ein Unterschied in der Grösse der Kerne Doch fand ich da kein konstantes Verhalten.

Was aber hauptsăchlich obne weiteres auffällt. wenn man eine grössere Anzahl dieser zweiköpfigen Spermien miteinander vergleicht, ist, dass die Köpfe nicht immer gleich weit oder völlig voneinander getrennt sind. Ebenso wie es unter den zweischwănzigen Spermien Formen gibt, deren Achsenfaden nur zum Teil erst aufgespalten ist, gibt es auch unter den zweiköpfigen Spermien solche, deren Köpfe noch zur Hälfte oder noch mehr miteinander verbunden sind, neben solchen, deren 
Köpfe bis zum Hals oder Verbindungsstück getrennt sind. Die Schwanzfäden können einfach oder auch doppelt sein; eventuell sieht man an ibnen die ersten Anzeichen einer beginnenden Aufspaltung. Das Verbindungsstiick ist entweder einfach, homogen, oder es lässt sich auch an ihm die beginnende Zerteilung nachweisen, oder es ist schon völlig in zwei Stücke zerfallen.

So kann man Doppelformen sehen, die eben nur noch durch eine letzte Protoplasmabrücke zwischen den Köpfen oder den Verbindungsstücken zusammenhängen, während sie im übrigen schon völlig getrennt sind (Fig. 27--29). Bei solchen Spermien, deren zwei Köpfe noch zum grösseren Teile miteinander verbunden sind, kann man bisweilen eine deutliche Scheidewand zwischen den Köpfen eventuell bis zum Halse hin wahrnehmen. Bei anderen, wo die Spaltung nur das vordere Kopfende betrifft, kann man eine solche Grenze nicht immer finden.

Die Möglichkeit, dass es sich dabei etwa um dicht aneinander gelagerte, selbständige Spermien handelt, lassst sich bei guter Färbung leicht ausschliessen, ganz abgesehen von dem Beweise, der im Vorkommen der verschiedenen Übergangsformen liegt.

\section{Mehrkernige Spermien.}

Durch diese Befunde war ich, noch bevor ich die Arbeiten von Broman und Retzius kannte, zu der - zunächst befremdenden - Ansicht gekommen, dass der Aufspaltungsprozess, dessen verschiedene Stadien sich an Kopf, Hals, Verbindungsund Hauptstïck nachweisen liessen, eventuell auch zu einer völligen Zweiteilung der Spermien führen könne. Es kam mir deshalb darauf an, das Verhalten des Kernes bei diesen Vorgången näher zu untersuchen, besonders darauf hin, ob etwa auch am Kerne Verănderungen nachzuweisen wären, die sich mit den Zerspaltungsvorgängen in Zusammenhang bringen liessen.

Ich untersuchte deshalb an besonders günstig gefärbten Präparaten die Kerne der grösseren Riesenspermien und fand, zunächst nur bei diesen, später aber auch bei weniger grossen Formen, dass sich bisweilen zwei Kerne im Kopfe nachweisen liessen (Fig. 18 bis 23). Solche zweikernigen Spermien findet man verhältnismässig nicht so selten. Die Kerne haben durchschnittlich dieselbe Grösse wie die der gewöhnlichen Spermien. Sie haben längliche, ovale, seltener breite, flache Form und 
liegen so im Kopfe, dass ihre Langsachsen - untereinander meist parallel - mit der des Kopfes zusammenfallen. Sie sind entweder voneinander durch einen deutlichen Protoplasmastreifen getrennt, oder sie stossen ganz dicht aneinander, sodass man eben gerade nur die Grenzlinie zwischen ihnen unterscheiden kann. Bisweilen schiebt sich auch der eine Kern mehr oder weniger weit über den anderen herüber. Doch kann man bei der Zartheit der Objekte die untere Grenzlinie sehr gut durch den darüber liegenden Kern hindurch verfolgen.

Dreikernige Spermien.

Nur zweimal habe ich mehr als zwei Kerne im Kopfe gesehen, nämlich drei (Fig. 46).

Sie waren ungefähr gleich gross, rund und scharf begrenzt. Der eine der Kerne liegt zum Teil über den anderen. Der Kopf zeigt am vorderen Pole einen herzförmigen Einschnitt. Zentrosomen sind nicht distinkt gefärbt, sondern Hals und Verbindungsstück haben eine diffuse dunkelblauviolette Färbung angenommen. Das Hauptstück war zwar einfach, aber stärker als normal. In Fig. 45 aber sieht man den grossen Kern deutlich in drei noch nicht völlig getrennte Teilstücke sich zerspalten. Die in den Spalten liegende Masse war dunkelviolett gefärbt. Auch hier zeigt die Plasmahülle seitlicb eine deutliche Einkerbung, als ob sie durch den zerfallenden Kern zersprengt würde. Hals, Verbindungs- und Hauptstück verhielten sich ebenso wie bei Fig. 46.

Bei den mebrkernigen Spermien boten Hals und Schwanzgeissel keinen typisch abweichenden Befund. Hals und Verbindungsstück waren selten deutlich voneinander abgesetzt. Das Verbindungsstück war meist stark verbreitert, besonders in den vorderen Abschnitten.

Übergangsformen.

Als Übergangsformen zwischen den zweikernigen Spermien und den zweiköpfigen glaube ich solche Formen betrachten zu dürfen, bei denen man am vorderen Kopfpole eine kleine Einkerbung im Protoplasma sieht, - wie mir scheint ebenfalls eine Andeutung von beginnender Zweiteilung des Kopfes (Fig. 17, 22, 23). So ist bei dem in Fig. $23 \mathrm{~b}$ abgebildeten Spermium 
ein deutlicher, herzförmiger Einschnitt am vorderen Kopfpole wahrzunebmen. Das Protoplasma umgibt seitlich in schmalen Streifen, vorn und binten in breiterer Ausdehnung, die beiden Kerne. Am vorderen Pole zieht sich, den Konturen der Kerne parallel laufend, ein herzförmiger Einschnitt in das Protoplasma herein, ohne jedoch tiefer in das Innere des Kopfes hineinzuführen. Auch ist zwischen den Kernen noch keine Andeutung einer Zellgrenze wahrzunehmen. Und zwar war dieser Finschnitt nur bei der Einstellung eines bestimmten optischen Querschnittes sichtbar, wobei unter inm noch die konvexe Kontur der darunter liegenden Teile des vorderen Kopfpoles hervorschien, während bei tieferer Einstellung nur eine ganz flache Einkerbung wahrzunehmen war; ein Zeichen dafür, dass die Einkerbung eben erst am vorderen, oberen Ende des Kopfes begonnen hatte. Unwahrscheinlich ist es mir, dass diese Einkerbung nur dadurch zu stande gekommen sein sollte, dass die beiden grossen Kerne das Zellplasma vorgebuchtet liaben. Denn erstens hat das Protoplasma wohl nicht so starre Konsistenz, und zweitens beginnt die Einkerbung eben nur an der einen Stelle des Kopfes.

Entstehung der mehrkernigen Spermien.

Die zweikernigen Spermien entstehen, wie ich glaube, durch Teilung eines einfachen Kernes. Ganz sichere Beweise kann ich für diese Annahme freilich noch nicht erbringen ${ }^{1}$ ).

In Fig. 10, 11 und 12 bilde ich Spermien ab, in deren Kerne ich Vorgänge wahrnehmen konnte, die den einer Mitose vorangehenden abneln. Es sind Riesenspermien mit so stark vergrössertem Kerne, dass sich, besonders bei den in Fig. 11 und 12 abgebildeten Spermien, nur stellenweise ein ganz schmaler Protoplasmasaum vorfand.

In Fig. 10 sieht man eine einfache dunkelgefärbte Schlinge auftreten. In Fig. 11 finden sich drei untereinander parallele Fäden, die distalwărts stärker beginnen und nach vorne zu fein auslaufen. Im Verbindungsstück liegen zwei miteinander ver-

1) Vergl. hierzu auch die Bemerkungen auf S. 35 und 39 bezüglich der äquatorial gelegenen chromatischen Körnchen und der Verteilung der chromatischen Substanz nach den beiden Kopfpolen.

Archiv f. mikrosk. Anat. Bd. 74. 
bundene Zentrosomkörner; der Verbindungsfaden lăuft noch ein Stück über das vordere Zentrosom hinaus nach dem Kopfe zu! Deutliche Kerngrenzen waren weder hier noch in Fig. $12 \mathrm{zu}$ sehen. Der Kopf war blaulich gefärbt, das Verbindungsstück batte eine mehr rötliche Furbung angenommen. In Fig. 12 sieht man einen mehrfach verschlungenen, feinen, zarter gefärbten Faden mit vielen eingestreuten, stărker tingierten Körnchen: Lininfaden mit Chromatinkörnern. Die Zentrosomen von Fig. 10 und 12 waren leider nicht distinkt gefärbt

Dagegen möchte ich die in Fig. 13 und 14 dargestellten Kernveränderungen nicht ohne weiteres auf mitotische Vorgänge beziehen. Ähnliche Bilder könnten sich auch bei einem Kernzerfalle ergeben.

Andererseits könnten Bilder wie Fig. 15-17 an Amitosen denken lassen. Man sieht hier deutlich eine verschieden weit in das Innere führende Einkerbung des Kernes, die aber noch nicht zu einer völigen Zweiteilung gefübrt hat. An den Zentrosomen ist dabei keine Veranderung wahrzunehmen. Fig. 17 zeigt noch einen sogen. "Schlussring". Ebenso ist bei Fig. 45 eine deutliche Zerspaltung des einfachen grossen Kernes in drei Teile zu sehen. Es bandelt sich hier wohl um eine Kernzerschnürung, wie sie ahnlich an den Leukozytenkernen auftritt.

Die Möglichkeit einer Mitose oder Amitose kann von vornherein wohl nicht abgelehnt werden.

Ich erinnere auch an die Befunde von mehrkernigen Eizellen beim Menschen (B. Schultze, Kölliker, Franqué [12]. Stöckel [34], H. Rabl [25], Schwarz und von Schumacher [32] u. andere). Stöckel hatte geglaubt für ihre Entstebung Amitosen annehmen zu müssen, da er keine Mitosen fand. Andererseits sind auch Mitosen, sogar mit beginnender Furchung, an den Eiern atretischer Follikel gesehen worden. Doch erübrigt es sich hier auf diese Frage năher einzugehen, bevor nicht weitere Befunde vorliegen.

$\mathrm{Ob}$ es sich bei diesen Teilungsvorgängen um degenerative Prozesse bandelt - analog den oben erwăhnten Vorgăngen in atretischen Follikeln, oder ob solche Teilungen auch physiologischer Weise vorkommen können, kann ich nach meinen Befurden nicht entscheiden. Dass es sicb in einzelnen Făllen um Kernzerfall handelt, ist $z$ weifellos. Es ergeben sich dann aber nicht scharf 
und glatt konturierte Kerne, sondern zackige Teilstücke. Jedenfalls ist kein Anhaltspunkt dafür vorhanden, dass es sich immer um pathologische Vorgänge handelt. Denn die Tatsache, dass sich alle solche Spermien in der Regel langsamer bewegen als die normalen, findet ihre ausreichende Erklärung schliesslich auch schon in den veränderten Form- und Grössenverbaltnissen und eventuell vorsichgehenden Teilungsprozessen. Andererseits liegt auch kein Grund vor, warum die Spermien, die schliesslich doch nichts anderes sind, als „zum Zweck der Lokomotion bistogenetisch umgeformte Spermatiden" (Waldeyer), die den vielen Generationen ihrer Vorläufer zukommende Befähigung zu einer physiologischen Teilung verloren baben sollten. O. Schultze (31) spricht gelegentlich der Erörterung von Ursachen für Doppelbildungen von „überreifen" Eiern, mit der Tendenz zur Fragmentation in zwei Hälften. Ganz entsprechend könnte man sich auch die Teilungsvorgänge bei den Spermien erklären.")

Es würden sich ja schliesslich auch alle die von mir beschriebenen abweichenden Formen als von vornherein atypisch entstandene und nicht weiter verănderliche Formen ansehen lassen. Ohne Zweifel ist ein Entstehen der atypischen Spermien in der von Broman angenommenen Weise sehr wohl möglich. Doch wäre, wenn man diese Entstehungsweise als die einzig mögliche annimmt, dann die Mannigfaltigkeit der Übergangsformen auffällig, und vor allem scheinen mir die an den Kernen gefundenen Strukturveranderungen und einige gleich noch $\mathrm{zu}$ besprechende Vorgänge an lebenden Spermien dagegen zu sprechen.

Die oben beschriebenen Vorgänge am Kerne sah ich fast immer nur an den vergrösserten Kernen von Riesenspermien. Hält man daneben noch die Befunde von den verschiedenen Übergangsformen von den einfachen, typischen Spermien zu den Spermien mit vergrössertem Kerne $=$ „Riesenspermien “, und von den einkernigen Riesenspermien zu den zweikernigen, und von

1) Es ist wohl der Hinweis nicht ohne Interesse, dass sich bei einigen Trypanosomenarten die physiologischen Teilungsvorgänge in ganz analoger Weise vollziehen: Es erfolgt entweder zuerst eine Verdoppelnng des Geisselfadens oder des Kernes. (Rabinowitsch-Kempner [24], Wassielewsky und Senn [36]). Es färbt sich nach Giemsa der Kern der Trypanosomen rot-violett, der Bewegungsapparat rot, die den Kern umgebende Zellsubstanz bläalich, die undulierende Membran mehr rosa. 
den zweikernigen, einschwänzigen Riesenspermien zu den zweiliöpfigen, zweischwanzigen Spermien und schliesslich bis zu den Doppelspermien (Fig. 28, 29), deren Teilspermien eben nur noch durch eine feine Protoplasmabrïcke miteinander verbunden sind so kann man die Möglichlieit eines Teilungsprozesses, der ja vielleicht nicht immer bis zur völligen Auseinanderlösung der Teilungsprodukte führ't, nicht a limine abweisen.

Andererseits wăre ja freilich auch die Auffassung möglich, dass es sich nicht um Teilung handele, sondern nur um das Auseinanderlösen zweier innig verschmolzen gewesener Spermien. Es blieben dann aber die von mir beobachteten besonderen Kernstrukturen (Fig. 10-17) und ebenso das Vorkommen dreikerniger Spermien zu erklaren.

\section{Beobachtungen an lebenden Spermien.}

Es lag nun der Gedanke nabe, ob es nicht möglich sei, unter dem Mikroskope eine solche Aufspaltung sich vollziehen resp. vollenden zu sehen, oder überhaupt irgendwelche Formveränderungen eintreten zu sehen. Meine Untersuchungen hierüber sind zwar noch nicht abgescblossen, doch will ich kurz schon hier über einige Beobachtungen berichten.

Es gelingt nicht immer an lebenden Spermien deutlich einen Kern zu sehen, auch wenn man sich vorher schon eingehend an gefärbten Prăparaten über die Kernformen unterrichtet hat. Nicht alle normalen Spermien zeigen eine Birnform des Kopfes. Man sieht an Spermien, die sich um ihre Langsachse drehen, sehr băufig, dass der Kopf immer dieselbe länglichovale Form beibehălt. Vielleicht ist dies auf eine Kernvergrösserung zurückzufübren. In Fig. $33 \mathrm{a}$ und b habe ich ein Spermium gezeichnet, das, selbst bewegungslos, durch Strömungen, die durch ein benachbartes Spermium verursacht wurden, um seine Lăngsachse gedreht wurde. Dabei erschien der Kern bei seitlicher Ansicht (Fig. 33 a) durch eine tiefgehende Einschnürung in zwei ungleich grosse, durch eine schmale Substanzbrücke verbundene Teile zertrennt, wăhrend sich nach einer Drehung um $90^{\circ}$ ein Bild wie in Fig. $33 \mathrm{~b}$ ergab. Da nun der vorn gelegene Teil des Kernes weniger stark lichtbrechend war, so hatte man den Eindruck, 
dass ein feiner zentraler Faden, etwa als Verlängerung des Achsenfadens - wie es Eimer und Bardeleben beschrieben haben -, oder als "Zentralstäbchen" (Miescher) durch den Kopf verliefe. Ähnliche Bilder ergaben sich auch bei zweikernigen Spermien, wo bei bestimmter Einstellung der zwischen den Kernen gelegene Protoplasmastreifen als hellglänzender Faden imponiert. Finige Male konnte ich auch eine Art von Syzygie (Ballowitz) bei den menschlichen Spermien sehen. Es können Bilder von zweiköpfigen zweischwänzigen oder auch solche von einköpfigen zweischwänzigen Spermien vorgetäuscht werden, so genau können sie übereinander gelagert sein. Ein leichter Druck lässt sie jedoch auseinanderweichen, sodass auch das darunterliegende Spermium zum Vorschein kommt (s. Fig. 38a-d). Äbnliche Bilder fand ich im gefärbten Präparat, wo sie nur schwer als zwei getrennte Individuen zu erkennen sind (Fjg. 31). Bei einer anderen Färbung hatte man hier unbedingt den Eindruck eines vierschwanzigen Spermiums mit atypischer Kopfbildung gebabt. Aber vielleicht handelt es sich in solchen Fallen auch um die Endstadien einer Zerteilung.

Es ist mir nun zwar nicht gelungen, eine Teilung vom Anfang bis zum Ende unter dem Mikroskope verfolgen zu können, aber ich konnte doch verschiedene Veränderungen und Umformungen an den Spermien eintreten sehen (Fig. 35-37, 39). So sah ich bei einem zweischwänzigen Spermium beide Hauptstücke sich nacheinander teilen (vgl. auch Fig. 35). Ebenso sah ich Umformungen an Kopf und Kernen, doch konnte ich diese nie bis zum Ende verfolgen. Doch hoffe ich, dass mir dies unter günstigeren Versuchsbedingungen (heizbarer Objekttisch etc) noch gelingen wird. Z. B. sah ich in einem zweischwänzigen Riesenspermium mit grossem, unregelmässig geformten, nicht homogenem Kerne nach Verlauf von einiger Zeit zwei Kerne sichtbar werden (Fig. 39 a und b). Weitere Veränderungen sah ich dann nicht mehr eintreten; inzwischen waren aber auch die Schwanzgeisseln bewegungslos geworden. Andere nicht leicht zu deutende Umformungen zeigen die Fig. 35 a und $b$. Dass es sich hier nicht etwa um zwei innig aneinandergelagerte, von Schleim eingehüllte Spermien handelt, beweist die scharfe Kontur dieser schwachlichtbrechenden Hülle und der Umstand, dass sie in den Umformungsprozess mit einbezogen wurde. Und der letztere Punkt 
bliebe auch zu erklären, falls man annehmen wollte, es handele sich um einen bei der Umbildung des Spermium aus der Spermatide hängen gebliebenen Protoplasmarest. Auffällig ist auch das Verhalten der Achsenfäden; und ebenso ist hervorzuheben, dass die in Fig. 35 b deutlich vorbandene spitze Schneide des vorderen Kopfpoles auch in Fig. 35 a erhalten ist. Überhaupt ist es bisweilen unmöglich, mit Sicherheit anzugeben, ob es sich um eine Kernteilung oder nicht vielmehr um eine vorübergehende Verschmelzung zweier Spermien handelt. Andere Umformungen zeigen auch die Fig. 36 und 37. Beachtenswert ist das Verhalten der Zentrosomen in Fig. 36. Eine besonders auffallige Kopfform, bedingt durch das Auftreten zweier ungleich grosser Kerne, zeigt Fig. 32 a und b; nach W. Krause soll die eine Seite des Hinterstückes des Kopfes nicht selten stärker konvex sein als die andere (zitiert nach Waldeyer). Fig. 34 zeigt einen stark lichtbrechenden Ring um die Mitte des Kopfes herum, wie er schon als "Grenze der Kopflkappe" beschrieben worden ist. Ein Kern war hier nicht wahrzunehmen. Möglicherweise besteht ein $\mathrm{Zu}$ sammenhang $z$ wischen diesem Ringe und dem oben beschriebenen Kranze feiner Körnchen.

II.

Zur Entstehung der Doppel(miss)bildungen.

Es ist ein naheliegender Gedanke, das Vorkommen atypischer Spermien mit der Entstehung atypischer Früchte in Verbindung zu bringen, sobald einmal das konstante Vorkommen der ersteren nachgewiesen ist. Und dieser Nachweis ist nicht schwer zu führen, wenn man über das nötige Untersuchungsmaterial verfügt.

Schon Cutler, Maddox und Bertachini (zitiert nach Broman) erwogen diese Möglichkeit und bringen die atypischen Spermien in Zusammenhang mit teratologischen Bildungen. Maddox bespricht auch - allerdings in ablehnendem Sinne die Möglichkeit, dass Doppelbildungen aus zweischwänzigen Spermien hervorgingen. Auch Ballowitz hat die Ansicht ausgesprochen, dass atypische Spermien wohl Missbildungen, Riesenwuchs und Doppelbildungen etc. veranlassen könnten (5 und.6). 
Doch, meint er, würden diese Annahmen vage Vermutungen bleiben, solange nicht bei einem geeigneten Tiermaterial unter dem Mikroskope kontrollierbare Befruchtungsversuche mit atypischen Spermien möglich sind. Broman hat sich in verschiedenen Arbeiten eingehend über eine mögliche Bedeutung der atypischen Spermien geäussert. Indem er sich auf $\mathrm{Be}-$ obachtungen Boveris stützt, glaubt er das Hauptgewicht bezüglich der "Befruchtungsfähigkeit" der Spermien auf das Vorhandensein normaler Zentralkörperderivate legen zu dürfen (11, S. 517 ff.). Darum wäre es ihm "auch nicht undenkbar, dass ein Ei von einer ganz kopflosen Spermie befruchtet werden könnte“; insofern noch unverletzte Zentralkörperderivate dem Schwanze aufsitzen (11, S. 518). Den mehrköpfigen Spermien schreibt er keine grössere Bedeutung für die Befruchtung zu, für den Fall, dass sich bei ihnen eine Behinderung in der Bewegung herausstellen sollte. Dagegen vermutet er, dass die zwei- und mehrschwänzigen Spermien, die nach Broman immer eine entsprechend vermehrte Anzahl von Zentralkörperderivaten haben, zur Bildung von Mehrfachbildungen Anlass geben könnten, „denn es ist möglich, dass die Chromatinmenge keine wesentliche Rolle für die Befruchtung spielt" (S. 523). Da er aber auf Grund seiner Annahme über die Entstehung zweischwänziger Spermien (nicht vollzogene Chromosomenverteilung in den Spermatocyten, siehe oben), vielen von ihnen eine vermehrte Chromatinmenge zuschreiben zu dürfen glaubt, so meint er, könnten sie auch dann noch als Ursache für die Entstehung von Doppelbildungen in Betracht kommen, wenn sich eine bestimmte Chromatinmenge als zur Befruchtung notwendig herausstellen sollte. Doch meint er, dass die Befruchtungsfähigkeit einer sich normal bewegenden Spermie viel mebr von den Zentralkörpern als von ihrer Chromatinmenge abhängt. Die Riesen- bezw. Zwergspermien aber könnten, wenn man das Chromatin als Erblichkeitsträger betrachtet, zu einer gesteigerten resp. herabgesetzten Vererbung väterlicher Eigenschaften führen. Ebenso könnte die anfängliche Grösse des werdenden Embryo von der Kopfgrösse der befruchtenden Spermie zum Teil abhăngen. Auch für die Entstehung von Missbildungen könnten die atypischen Spermien die Veranlassung geben.

Bevor ich die Schlussfolgerungen mitteile, die, wie es mir scheint, die von mir gefundenen Tatsachen erlauben, will ich kurz 
die verschiedenen bisher gegebenen Deutungsversuche für die Entstehung eineiiger Zwillinge besprechen, wobei ich im allgemeinen der Darstellung Sobottas (23) folge.

Dass eineiige Zwillinge wirklich aus einer einzigen Eizelle entstehen, dafür sprechen verschiedene Anzeichen : das ausnahmslos gleiche Geschlecht, die weitgehende Ähnlichkeit, die sich angeblich sogar auf geistige Eigenschaften erstrecken soll, und ferner das Verhalten der Einäute: das Amnion ist bisweilen, das Chorion aber stets gemeinsam.

\section{Die Entstehung von Doppebildungen durch Polyspermie.}

Gegen die Möglichkeit einer Dispermie, also Befruchtung durch mehr als ein Spermium, lässt sicb einwenden, dass nach den bisherigen Erfahrungen „das Eindringen mehrerer Samenfäden entweder wie bei den kleinen dotterarmen Eiern schwere Entwicklungsstörungen hervorruft und jede weitere Entwicklung der Fizelle überbaupt verhindert, oder bei grossen, dotterreichen Eiern, bei denen die Polyspermie zumeist mehr oder weniger physiologisch ist, doch nur stets ein einziger der eingedrungenen Samenfäden mit dem Eikerne kopuliert" (Sobotta). Dagegen fand Boveri, dass sich bei künstlicher Überbefruchtung mit mebreren Spermien sich auch mehrere Spermakerne mit dem Eikerne vereinigten. Jedes Spermazentrosom liefert zwei Tochterzentrosomen und es entsteht statt der zweipoligen Teilungsfigur eine vier- oder mebrpolige. Freilich sah er nie aus einem so befruchteten $\mathrm{Ei}$ eine Entwicklung weiter als bis zur Zellenblase vor sich gehen. „Wo immer in einer Zelle mehrpolige Teilungsfiguren entstehen, ist das Produkt ein patbologisches." Dabei ist aber, wie mir scheint, daran zu erinnern, dass solche Überbefruchtungsversuche, soweit sie an Eiern vorgenommen werden, die vorher, um die Überbefruchtung an ihnen zu ermöglichen, mit Narkoticis oder Giften künstlich geschwächt sind, nicht als eindeutig anzusehen sind, und die Entwicklungshemmung nicht ohne weiteres der Polyspermie zur Last fällt. Aber die Möglichkeit einer Dispermie auch zugegeben, so würde sich dadurch die Entstehung von $Z$ willingen mit den oben angegebenen Eigenschaften doch nicht erklären lassen. 
II. Entstehung aus zweikernigen Eizellen.

Schon B. Sc bult z e nahm an, dass alle menschlichen Doppelbildungen aus zweikernigen Eiern entstehen. Auch Kölliker besprach diese Möglichkeit in seiner Entwicklungsgeschichte. Neluerdings hat Franqué (12) nach Befunden von zweikernigen Eiern im Ovarium von Erwachsenen diesen Gedanken wieder aufgenommen. Dagegen meinte Stöckel (34), der auf Veranlassung voll Marchand ein Ovarium untersuchte, das mehrfach solche Bildungen enthielt, dass die zweikernigen Eier für die Entstehung von eineiigen Zwillingen nicht in Betracht kämen, weil er fand, dass aus ihnen noch zwei getrennte Follikel hervorgehen konnten. Es zwingt aber nichts, anzunehmen, dass eine solche Eiteilung immer vor voliendeter Eireifung eintreten müsse. Andere Forscher (H. Rabl u. a.) haben zweikernige Eier noch in sprungreifen Follikeln gesehen. (Nach $\mathrm{Rabl}$ waren sie übrigens durch Verschmelzung zweier Eier entstanden.)

Jedenfalls stehen aber dem Versuche, die Entstehung von Doppelbildungen aus solchen Eiern zu erklären, noch andere Bedenken entgegen. Die Schwierigkeit ist, wie Sobotta ausführt, gleich gross, ob man nun annimmt, dass ein solches Ei von einem, oder dass es von zwei Spermien befruchtet wird. Im Falle einer Dispermie wăre es nach Sobotta kaum denkbar, wie sich eine doppelte normale Furchungsspindel in einem Ei ausbilden und eine regelrechte gleichzeitige Teilung des Eies in vier einkernige Tochterzellen erfolgen könne. (Die neueren Versuche Boveris [s. oben] lassen ein solches Vorkommnis schon eher möglich erscheinen.) Aber, diese Möglichkeit auch zugegeben, so würde eine Dispermie ja gerade eben das nicht erklären können, was für eineiige $Z$ willinge charakteristisch ist: das gleiche Geschlecht und die grosse geistige und körperliche Ähnlichkeit. Wolle man aber annehmen, dass nur ein Spermium bei der Befruchtung in Frage käme, so könnte doch in dem Falle auch nur der eine Kern befruchtet werden, wăhrend sich der andere parthenogenetisch entwickeln müsste. Überdies würden die gleichen Schwierigkeiten wie im anderen Falle bestehen bleiben.

Broman glaubt nun, dass bei der Annahme einer Befruchtung solcher Eier durch zweischwänzige Spermien sich solche Schwierigkeiten nicht ergeben würden. Da man aber im Chromatin den Träger der Vererbung sieht, so müsste dann doch 
noch die weitere Annahme gemacht werden, dass in solchen Fällen das Spermium jedesmal auch die den beiden Eikernen aquivalente Chromatinmenge führt, was aber eben erst an den Spermien noch nachzuweisen wäre. In dem Falle würde dann auch das ausschlaggebende Moment nicht in der Zweischwänzigkeit resp. in dem der Mehrschwänzigkeit entsprechenden Vorhandensein vermehrter Zentralkörperderivate $\mathrm{zu}$ suchen sein, sondern darin, dass sich hier eine doppeltäquivalente Chromatinmenge im Spermiumkopf vorfände, abgesehen von den anderen, vielleicht anch schon entsprechend vermehrten Zellbestandteilen.

III. Entstehung aus isolierten ersten Blastomeren.

Dass Doppelbildungen auch aus isolierten ersten Furchungszellen entstehen könnten, könnte man auch aus den Versuchen schliessen, die ersten beiden Blastomeren zu trennen resp. eine von ihnen abzutöten. Nach Driesch kann aus jeder der ersten Furchungszellen des Seeigeleies eine Ganzlarve entstehen, während Roux auf Grund seiner Versuche am Froschei zu dem Resultate gelangte, dass jede der ersten beiden Furchungszellen nur einen Halbembryo zu erzeugen imstande sei. Auch Boveri hat durch neuere Untersuchungen festgestellt, dass auch die ersten Blastomeren des Seeigeleies nur unter gewissen Bedingungen aquipotent sind. Nach R. Hertwig (15, S. 586) hat neine auf dem Zweizellenstadium isolierte Blastomere zwar die Făhigkeit, einen ganzen Organismus aus sich heraus zu erzeugen, dagegen im Moment der Isolierung die Anordnung der Zellteile, welche nötig ist, um die für die Hålfte eines Organismus bestimmte Gruppierung des Zellmaterials hervorzurufen. Was nun tatsächlich aus der Blastomere werden wird, hängt ausschliesslich von der Stabilität des Zellgefüges $a b^{\text {". B }}$ B overi (zitiert nach W aldeyer) konnte den sicheren Nachweis führen, dass bei Ascaris megalocephala schon bei der ersten Zweiteilung des Eies eine Differenzierung der Art eintritt, dass ausschliesslich in der einen Furchungszelle (Stammzelle I. Ordnung) die Anlage der späteren Geschlechtszellen, der männlichen wie der weiblichen, ihren Sitz hat, während aus der anderen Zelle (somatische Urzelle) nur Gewebszellen des Embryo hervorgehen.

Beweise für oder gegen eine solche Äquipotenz der ersten Blastomeren bei den Säugetieren besitzen wir natürlicherweise 
nicht. Aber selbst bei der Annahme einer Äquipotenz würden, wie Sobotta ausführt, andere Tatsachen es verbieten, aus einer Trennung der beiden ersten Furchungszellen die Entstehung von Doppelbildungen abzuleiten. Man hätte, abgesehen von anderen Bedenken, dann nämlich ausser doppelten Amnien auch doppelte Chorien zu erwarten. Möglich dagegen wăre es, dass eineige Zwillinge nicht aus eigentlich isolierten ersten Blastomeren entstehen, sondern so, dass nur das zur Embryonalbildung dienende Material völlig getrennt wird, nicht aber dasjenige, welches die Eihäute bildet.

\section{Entstehung aus doppelter Embryonalanlage.}

Es besteht auch die Möglichkeit, dass Doppelbildungen aus Störungen im Verlaufe der spăteren Furchung oder während des Keimblasenstadiums entstehen können. Fälle von mehrfacher Embryonalanlage auf einer Keimblase - also aus einem Ei entstanden, sind bei Säugetieren schon beobachtet worden. Doch ist die Ursache, die eine solche doppelte Anlage entstehen lässt, noch unbekannt. Dass die Ursache auf einem früheren Stadium zu suchen ist, als wo die Doppelbildung der direkten Beobachtung zugänglich ist, d. h. im Gastrulastadium, daran ist nach S o bot ta nicht zu zweifeln. Es könnten etwa im Zweizellen- oder späteren Furchungsstadium Störungen eintreten, die zu einer Zellverlagerung führen, und dies könnte die Ursache für das Auftreten eines doppelten Embryonalfleckes auf der Keimblase sein.

\section{Schlussfolgerungen.}

Eineiige Zwillinge sind beim Menschen relativ häufig: einmal auf 600-700 Geburten (Sobotta). Es müsste sich also auch um ein verursachendes Moment handeln, das recht häufig zur Einwirkung gelangen kann, also, bei der geschützten Lage des Eies, vermutlich keine ăussere, eine Zellverlagerung bewirkende Ursache. Andererseits darf man annehmen, dass die Ursache schon in den frühesten Stadien zu suchen ist, eventuell schon im Zweizellenstadium. Nach Marchand (18) ist die Verdoppelung der Anlage auf Zustände zurückzuführen, welche noch vor den Beginn der Furchung fallen, also entweder auf Zustănde des Eies vor der Befruchtung oder auf die Befruchtung selbst. 
Die anatomische Grundlage der eine Doppelbildung verursachenden Vorgänge, glaube ich, wenigstens für eine grosse Anzahl von Făllen, in den von mir beschriebenen zweikernigen Spermien und andererseits auch in den zweikernigen Eiern sehen zu dürfen.

Die zweikernigen Spermien und die Formen, aus denen, wie ich vermute, die zweikernigen hervorgehen, sind beim Menschen nicht so selten. Und auch die zweikernigen Eier sind von neueren Untersuchern doch häufiger gefunden, als man im Anfange geglaubt hatte. Dass solche Eier aber auch wirklich eine normale Reife in bezug auf beide Kerne erreichen können, darf man wohl annehmen. Rubaschkin (28), der zweikernige Fier bei Meerschweinchen hăfiger sah, beschreibt bei ihnen die Bildung multipolarer Richtungsmitosen und das Auftreten $z$ weier Richtungsspindeln in einem Ei. Auch fand man solche Eier beim Menschen in sprungreifen Follikeln. Andererseits ist es aber auch nicht unmöglich, dass eine Kernteilung auch noch zur Zeit des Follikelsprunges eingeleitet wird, oder vielleicht auch noch nachher. Auch O. Schultze (31) vermutete, dass die Ursache für Doppelbildungen möglicherweise in der Anwesenheit von zwei Kernen bezüglich zweier Richtungsspindeln im Ei, oder in der Überreife des Eies mit Tendenz zur Fragmentierung in zwei Hălften, die sich kurz vor der Befruchtung teilen, gelegen sei.

Nehmen wir nun zuerst den Fall an, dass ein zweikerniges $\mathrm{Ei}$ durch ein zweikerniges Spermium befruchtet würde. ${ }^{1}$ ) Das Eindringen eines solchen Spermium in ein zweikerniges gesundes $\mathrm{Ei}$ ist selbstverstiandlich möglich Eine Dispermie im gewöhnlichen Sinne liegt hier nicht vor, dieser Befruchtungsvorgang brauchte deshalb auch nicht als ein pathologischer betrachtet $z u$ werden. Die Weiterentwicklung von Eiern niederer Tiere bei Polyspermie bis zu einem bestimmten Grade ist von Boveri (siehe oben) u. a. beobachtet worden. Doch handelte es sich da um pathologische Vorgange. In unserem Falle aber liegen die Verhăltnisse ganz anders, und die aus solchen Versuchen gezogenen Schlüsse können auf Vorgänge, wie ich sie eben andeutete, nicht ohne weiteres übertragen werden. Die Weiterentwicklung eines so befruchteten Eies erscheint also nicht als unmöglich.

1) Vgl. hierzu auch die ähnlichen Ausführungen B romans. 
Es ist nun müssig zu fragen, wie die Vorgänge bei einer solchen Befruchtung zu denken wären: ob Verschmelzung der vier Kerne zu zwei Furchungskernen, Bildung von zwei Furchungsspindeln, oder Verschmelzung zu einem Furchungskerne mit nachfolgender Bildung einer einfachen oder mehrpoligen Spindel etc. Aber eines darf man wohl als sicher annehmen, dass die so etwa entstandenen zwei oder vier ersten Teilungsprodukte den normalerweise entstehenden ersten Blastomeren nicht gleichgesetzt werden dürften. Denn es würde hier, abgesehen von den übrigen Zellbestandteilen, doppelt so viel Kernsubstanz zur Vereinigung kommen als gewöhnlich. Es wären also die etwa entstehenden zwei Furchungskerne oder Furchungsspindeln, als aus gleichwertigen Bestandteilen hervorgegangen, einander gleichwertig, und ebenso müssten die aus ihnen hervorgehenden Tochterzellenpaare einander gleichwertig sein. Es hätten sich also nicht die vier ersten Blastomeren ergeben, sondern zwei Paare der ersten zwei Blastomeren. Diese Paare wären dann äquipotent, und es würden sich aus ihnen - einen normalen Entwicklungsverlauf vorausgesetzt - zwei Früchte entwickeln. Entsprechend würden, wenn es etwa zunächst nur zu einer Zweiteilung des Eies käme (wie es in anderen Fällen [s. unten] vielleicht möglich wäre), zwei ăquipotente Tochterzellen entstehen, aus denen erst die gewöhnlichen ersten Blastomeren hervorgehen würden.

Eine völlige Isolierung dieser ersten Zellen braucht nicht einzutreten: dafür liegt einerseits gar kein Grund vor, und es würde auch andererseits die Zona pellucida einer solchen Isolierung doch einen gewissen Widerstand entgegensetzen, sondern sie könnten auch im weiteren Verlaufe der Furchung noch miteinander vereinigt bleiben und zum Teil gemeinsame Eihäute bilden: nur ist eben von vornherein eine Doppelbildung angelegt, und es wird die dauernde Tendenz zu einer Trennung bestehen, die dann in einem späteren Entwicklungsstadium erfolgen kann, etwa infolge spezieller Wachstums- oder Grössenverhältnisse. Die Zona pellucida, die anfänglich einer Trennung einen gewissen Widerstand entgegensetzte, kommt ja späterhin auch zum Schwinden.

So entstandene eineiige $Z$ willinge würden alle bekannten charakteristischen Merkmale aufweisen.

Nimmt man nun ferner an, dass die Trennung der beiden entstehenden Embryonen aus irgend einem äusseren, etwa Raum- 
mangel, oder inneren Grunde nicht vollständig erfolgen kann, sondern dass etwa eine grössere oder geringere Verschiebung und Verlagerung von Zellen aus beiden Zellhaufen stattgefunden hat: so wären hiermit die Bedingungen zur Entstehung von mehr oder weniger miteinander verbundenen und verstümmelten Doppelmissbildungen gegeben.

Freilich lassen sich gewiss nicht alle Doppelmissbildungen so erklären. Und ebenso ist die angezeigte wohl lraum die einzige Möglichkeit für das Entstehen von Doppelbildungen. Immerhin glaube ich doch wenigstens eine Möglichkeit nachgewiesen zu haben, wie man sich die Entstehung eineiiger Doppel (miss) bildungen erklären könnte.

Es erübrigt sich, diese Hypothesen, denen keine anatomischen Befunde entsprechen, weiter auszuführen. Es soll nur noch darauf hingewiesen werden, dass sich ăhnliche Verhältnisse, wie die eben beschriebenen, ergeben können, wenn bei der Befruchtung Eier und Spermien zusammentreffen, deren Kern sich in den Vorstadien der Teilung befindet, oder "überreife" Eier und Spermien mit der Tendenz zur Teilung; oder auch solche Eier bezw. Spermien mit zweikernigen Spermien bezw. Eiern usf.

Noch zwei Schlussfolgerungen möclte ich kurz anführen. Es erscheint nicht ausgeschlossen, dass in solchen Fällen, wo nicht, wie gewöhnlich, åquivalente, sondern verschieden grosse Mengen von Kernsubstanz im Oospermium zusammentreffen, diese Mengendifferenz zur Vererbung von vorwiegend vaterlichen oder mütterlichen Eigenschaften führt.

Und ebenso wäre es möglich, dass diese Mengendifferen $z$ oder der Unterschied im Zustande der Reife bezw. "Überreife" von Ei und Spermium (s. oben) einen Einfluss hinsichtlich der Geschlechtsbestimmung ausüben könnten ${ }^{1}$ ). Dies würde dann

1) Die Frage, ob die z.Zt. der Befruchtung schon "überreif" gewordenen, sich einem Degenerationsstadium nähernden Geschlechtszellen an Einfluss auf die Geschlechtsbestimmung verlieren, würde sich vielleicht durch eine statistische Untersuchung z. T. aufklären lassen. Es wäre zu eruieren, wieviel Zeit zwischen befruchtendem Coitus und Befruchtung einerseits and zwischen der vermutlich in Betracht kommenden Ovalation und Befruchtung andrerseits vergangen ist; und zu untersuchen, ob unter gleichen Verhältnissen sich eine gleichartige Beeinflussung der Geschlechtsentwicklung zeigt. (Über ähnliche Untersuchungen s. bei $R a u b e r$ [26].) Es wäre freilich zu berück- 
möglich sein, wenn eine eingeschlechtliche Potenz der reifen Sexualzellen bestünde, sei es nun, dass sie die Anlage zum entgegengesetzten Geschlecht in sich schliessen oder aber die zum gleichen. Letzteres kann, wie mir scheint, in Anbetracht des innigen Zusammenhanges zwischen Ausbildung der Geschlechtszellen einerseits und der Geschlechtscharaktere andererseits nicht ohne weiteres abgelehnt werden, wenn sich auch nicht, wie für den umgekehrten Fall, Beispiele aus der Tierwelt dafür anführen lassen. Ferner müssten dann von den zwei Arten geschlechtsbestimmender Faktoren - repräsentiert durch irgend einen Zellresp. Kernbestandteil -, die bei der Befruchtung dem Oospermium zugeführt werden, der eine im Verlaufe der Heranbildung der Sexualzellen eliminiert werden oder funktionell zurücktreten. Und hierfür könnten dann -... unter anderen - auch die oben angeführten Momente Veranlassung geben.

Mit diesen Ausführungen würden sich auch die wichtigen Befunde von $\mathrm{Rückert}$ und Hăcker $(29,14 \mathrm{a} \mathrm{u}$. b) in Einklang bringen lassen. Häcker konnte eine Fortdauer der Selbständigkeit der văterlichen und mütterlichen Kernsubstanz vom befruchteten $\mathrm{Ei}$ bis zu den Fortpflanzungszellen nachweisen. Und da er fand, dass in den Urgenitalzellen von Cyclops die Chromatinsubstanz der beiden Kernbälften eine ungleiche physiologische Beschaffenheit annahm, so schloss er, dass die beiden Kernhälften „in einer Art von Konkurrenz hinsichtlich der Beherrschung des Zelllebens" stünden, was auch hinsichtlich des Problems der Geschlechtsbestimmung von Interesse wäre. Ferner kommt er (14b) zu dem Schlusse: „dass es im Kerne mannliche und weibliche Untereinheiten gibt, und dass jeweils die Majorität derselben ausschlaggebend ist", ohne auf das Zustandekommen einer solchen Majorität weiter einzugehen.

Finen ähnlichen Gedanken enthält auch die Balfour-, Minot-, van Benedensche Theorie vom Hermaphroditismus sichtigen, dass sich in jedem Ejakulate neben reifen auch schon degenerierende Spermien finden. Entsprechend würde sich ein Beweis bei künstlicher Befruchtung im Tierexperiment führen lassen.

Ebenso wäre es denkbar, dass sich auch Schädigungen für das entstehende Individuum ergeben können, wenn bei der Befruchtung Ei oder Spermium sich schon einem Degenerationsstadium nähern, wobei die Möglichkeit zum Zustandekommen einer Befruchtung noch nicht aufgehoben zu sein braucht. (Vergl. auch: Zeugung im Alkoholrausch.) 
der Zelle, nämlicb dass die „hermaphroditen " Kerne der unreifen Geschlechtszellen während des Heranreifens ibre männlichen bezw. weiblichen Halften ausstossen (womit dann die Vorgänge der Richtungskörperbildung in Zusammenhang gebracht wurden).

Die Erscheinungen der Parthenogenese und des Hermaphroditismus würden, wie mir scheint, der oben kurz ausgeführten Hypothese nicht widersprechen. Und ebenso würde sich das gleichzeitige Vorkommen von männlichen und weiblichen Eiern im Ovarium mancher Tiere entweder so erklaren lassen, wie oben angedeutet wurde, oder durch die Annahme einer Differenzierung der in den früheren Stadien zugleich enthaltenen zwei Arten von geschlechtsbestimmenden Faktoren auf die zwei Arten von Eiern. Vergl. Raubers (26) Annabme einer asymmetrischen Zellteilung geschlechtlich indifferenter Voreier bei Dinophilus und Weismanns Theorie der erbungleichen Zellteilung.

Diese Fragen können jedoch hier nur kurz gestreift werden, eine weitere Erörterung derselben würde aus dem Rahmen der vorliegenden Untersuehung fallen.

\section{Literaturverzeichnis.}

1. A u erbach, Leopold: Über einen sexuellen Gegensatz in der Chromatophilie der Keimsubstanzen. Sitzungsber. d. Akad. d. Wissensch., Berlin 1891.

2. Ballowitz, E.: Die innere Zusammensetzung des Spermatozoenkopfes der Säugetiere. Zentralbl. f. Physiol, 1891.

3. Derselbe: Untersuchungen über die Struktur der Spermatozoen. Arch. f. mikrosk. Anat., Bd. XXXII, 1888.

4. Derselbe: Weitere Beobachtnngen über den feineren Bau der Säugetierspermatozoen. Intern. Monatsschrift f. Anat. u. Phys., Bd. VII, 1890.

5. Derselbe: Notiz über Riesenkerne. Anat. Anz., Bd. XVII.

6. Derselbe : Über das regelmässige Vorkommen zweischwänziger Spermien im normalen Sperma der Säugetiere, Anat. Anz., Bd. XX, 1902.

7. B a r del eben, K. v.: Über den feineren Bau der menschlichen Spermatozoen. Verh. d. Anat. Gesellsch., München 1891.

7a. Derselbe: Beiträge zur Histologie des Hodens and zur Spermatogenese beim Menschen. Arch. f. Anat. u. Entwicklungsgesch., 1897.

8. Beard, J.: The determination of sex in animal development. Anat Anz., Bd. XX, 1902.

9. Boveri: Das Problem der Befruchtung. 1902. 
10. Broman, J.: Über Bau und Entwicklung von physiologisch vorkommenden atypischen Spermien. Anat. Hefte, Bd. XVIII, 1902.

11. Derselbe: Über atypische Spermien (spez. beim Menschen) und ihre mögliche Bedeutung. Anat. Anz, Bd. XXI, 1902.

11a. Eberth, C. J.: Dic männlichen Geschlechtsorgane. Bardelebens Handb. d. Anatom. d. Menschen, Bd. VII.

12. Franqué, v.: Beschreibung einiger seltener Eierstockspräparate. Zeitschrift f. Geburtshilfe und Gynäkol., Bd. XXXIX, 1898.

13. Grohe, F.: Über die Bewegung der Samenkörper. Virchows Archiv f. pathol. Anat, Bd. XXXII, 1865.

14 a. H a e c ker, V.: Über die Autonomie der väterlichen und mütterlichen Kernsubstanz vom Ei bis zu den Fortpflanzungszellen. Anatom. Anz.: Bd. XX, 1902.

14b. Derselbe: Über das Schicksal der elterlichen und grosselterlichen Kernanteile. Jenaische Zeitschr. f. Naturwissensch., 190:3, Bd. 37; N. F., Bd. 30.

15. Hertwig, R.: Eireife und Befruchtung. Handb. d. vergl. u. experim. Entwicklungslehre d. Wirbeltiere. I. 1. a, Kap. II.

16. J e n s e n, O. S.: Die Struktur der Samenfäden. Bergen 1879. (Berlin b. Friedlaender.) Zit. nach $\mathrm{W}$ aldeyer.

17. Il a n n, G.: Über die Behandlung der Nervenzellen f. exper.-histol. Untersuchungen. Zeitschr. f. wissensch. Mikroskopie, Bd. 11, 1894.

18. M a r ch and: Missbildungen. Eulenburgs Realencyklopädie, Bd. XV, 1897.

19. M e ve s : Über oligopyrene und apyrene Spermien. Arch. f. mikr: Anat. u. Entwicklungsgesch., Bd. 61, 1903.

20. Derselbe: Zur Entstehung d. Achsenfäden menschl. Spermatozoen. Anat. Anz., Bd. 14, 1897.

21. Derselbe: Über Struktur und Histogenese der Samenfäden des Mcerschweinchens. Arch. f. mikr. Anat., Bd. 5 1899.

22. M i e s h er, Fr.: Die Spermatozoen einiger Wirbeltiere. Histochem. u. physiol. Arbeiten, Bd. II, 1897.

23. P a p p e h e i m, A.: Färbetechnisches zur Kenntnis d. Spermatosomata hominis. Biolog. Zentralbl., Bd. XX, 1900.

24. Rabinowits $\mathrm{ch}$ und Kempner: Rattentrypanosomen. Zeitschr. f. Hyg., Bd. 30, 1899.

25. R a b 1, H.: Mehrkernige Eizellen und mehreiige Follikel. Arch. f. milkr. Anat. u. Entwicklungsgesch., Bd. $\check{4} 4,1899$.

26. $\mathrm{R}$ a u b e $\mathrm{r}$, A.: Der Überschuss an Knabengeburten und seine biologische Bedeutung. 1900.

27. Retzius: Zur Kenntnis der Spermatozoen. Biolog. Untersuch., 1881.

28. R u b a s chkin, W.: Über die Reifungs- und Befruchtungsprozesse des Meerschweincheneies. Anat. Hefte, H. 89, Bd. 29, 1905.

29. R ü c k e r t, J.: Über das Selbständigbleiben der väterlichen und mïtterlichen Kernsubstanz während der ersten Entwicklung des beobachteten Cyclops-Eies. Arch. f. mikr. Anat., Bd. 45, 1895.

30. $\mathrm{S} \mathrm{ch} \mathrm{minke,A.:} \mathrm{Über} \mathrm{Ruminantierspermien} \mathrm{und} \mathrm{ihre} \mathrm{Bewegang.} \mathrm{Arch.}$ f. mikr. Anat., Bd. 63 .

Archiv f. mikrosk. Anst. Bd. 74. 
31. Schultze, 0.: Entwicklung der Doppelbildungen. Zentralbl. f. allg. Pathol., Bd. X, 1899.

32. v. Schumacher und Schwarz: Mehrkernige Eizellen und mehreiige Follikel. Anat. Anz., Bd. 18, 1900.

33. S o b o t ta: Neuere Anschauungen über die Entstehung der Doppel(miss)bildungen Würzburger Abhandlg. a. d. Gesamtgeb. d. prakt. Med., 1901.

34. Stoeckel: Über Teilnngsvorgänge in Primordialeiern bei einer Erwachsen. Arch. f. milkr. Anat., Bd. 53.

35. Wa ld e yer: Die Geschlechtszellen. Hertwigs Handb. d. Entwicklungsgeschichte d. Wirbeltiere, I. 1. a, Kap. I, 1901.

36. Wassielewsky und Senn: Flagellaten d. Rattenblutes. Zeitschr. f. Hyg , Bd. 33, 1900.

\section{Erklärung der Abbildungen auf Tafel II--IV.}

Fig. 32-42 wurden nach lebenden Spermien gezeichnet, Fig. 40-42 nach vorhergehendem Zusatz von Azur II, die übrigen Figuren nach mit Jenners Farbstoff gefärbten Ausstrichpräparaten (Zeiss' Apochrom.-Immers., Komp.Ok. 8-12, vereinzelt 18 ).

Anmerk: Die Schwanzfäden der Spermien sind nicht bis zum Endstück ausgezeichnet. Die Kopfgrösse ist nicht immer in demselben Måstabe wiedergegeben.

\section{Tafel II.}

Fig. 1-9 Verschiedene Kernformen.

Fig. 10-12. An Mitose erinnernde Vorgänge im Kern von Riesenspermien.

Fig. 13-14. Ähnliche Befunde.

Fig. 15-17. An Amitose erinnernde Kerneinschnürungen.

Fig. 18-23. Zweikernige Spermien. Fig. 22 u. 23 zeigen am vorderen Kopfpole eine seichte Einkerbung. Fig. 23 a und b sind bei verschiedener Einstellung gezeichnet; 23 a zeigt eine beginnende Aufspaltung des Schwanzes, $23 \mathrm{~b}$ eine Einkerbung des vorderen Kopfpoles.

\section{Tafel III.}

Fig. 24-26. Übergangsformen von den zweikernigen zu den zweilöpfigen Spermien. Fig. 24 durch Farbstoffniederschläge zum Teil überlagert.

Fig. 27-30. Zweiköpfige Spermien, verschieden weit auseinander gelöst.

Fig. 31. Zwei dicht ïbereinander gelagerte Spermien, die zunächst den Eindruck eines vierschwänzigen Riesensperminm machten.

Fig. 32-39. Zeichnungen nach lebenden Spermien.

Fig. 32 a u. b. Zweikerniges Spermium bei verschiedener Einstellung.

Fig. 33a u. b. Spermium mit Kerneinschnürung bei seitlicher und Flächenansicht. 
Fig. 34. Ringbildung.

Fig. 3ら-39. Unter dem Mikroskope beobachtete Umformung an Spermien.

Fig. 68. Zweiköpfiges Spermium. Verdicktes Verbindungs- und Hauptstück, wie in beginnender Aufspaltung. (Photogramm. In Grösse des Photogr. $)^{1}$ )

\section{Tafel IV.}

Fig. 40-42. Beobachtungen an lebenden Spermien nach Zusatz von Azur II. Fig. 43-67. Färbung nach J enner.

Fig. 43. Spermium mit herausgepresstem Kerne.

Fig. 44. Zweikerniges Spermium.

Fig. 45. Spermium mit dreifach eingeschnürtem Kerne.

Fig. 46. Dreikerniges Spermium.

Fig. 47 u. 48 . Sper'minm mit Kranz feiner Körnchen; Fig. 47 zeigt eine streifige Figur des Kernes.

Fig. 49. Kern mit zwei grösseren Körnchen.

Fig. 50-67. Zentrosomen und Zentrosomfäden.

Fig. 59 u. 61 . Am vorderen Kopfpole Körnchen von gleichem Verhalten wie die Zentrosomen.

1) Photngramme für die Figuren $10,21,23 a \mathrm{u}$. b. 43 stelle ich gerne zur Veríügung. 


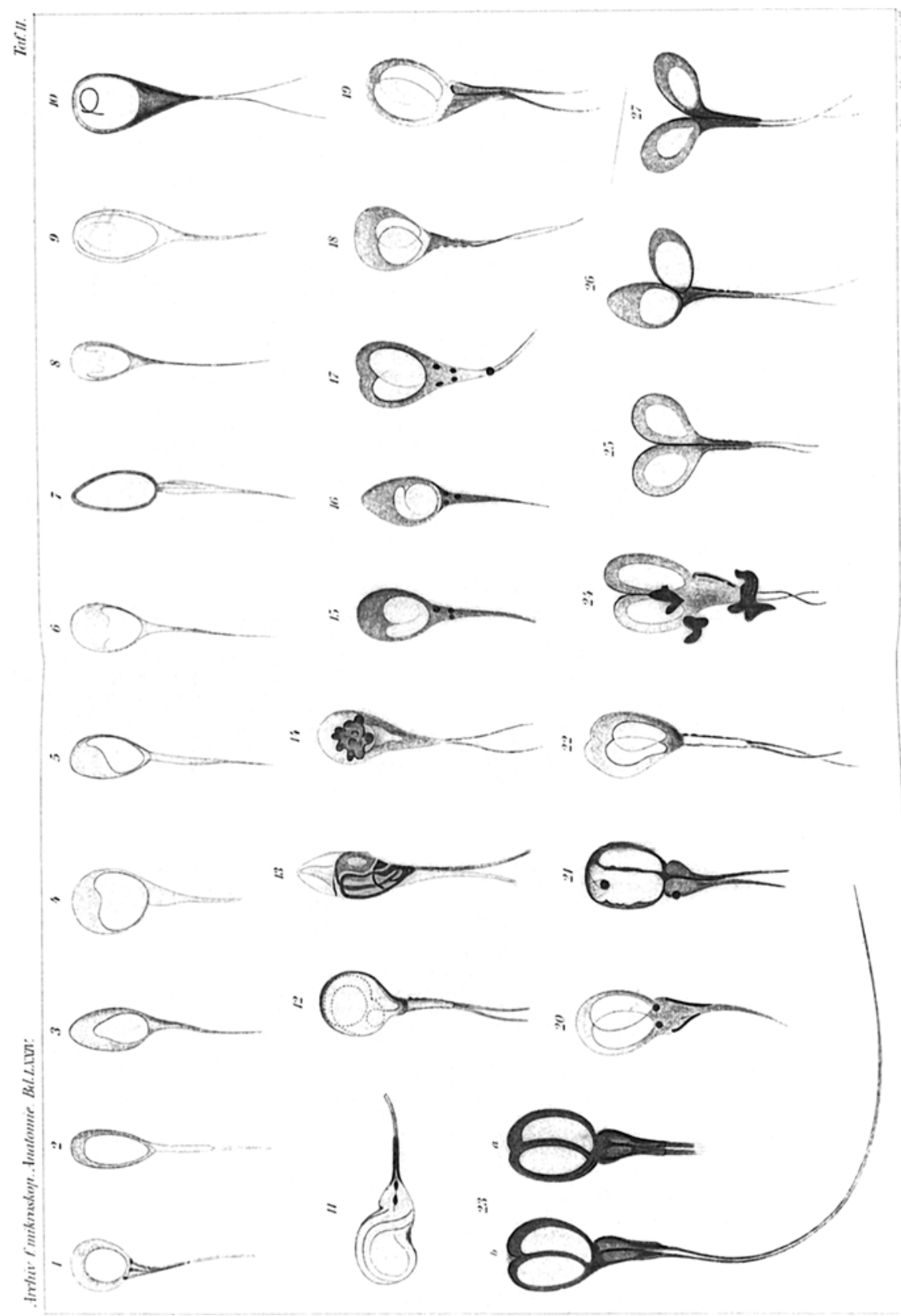




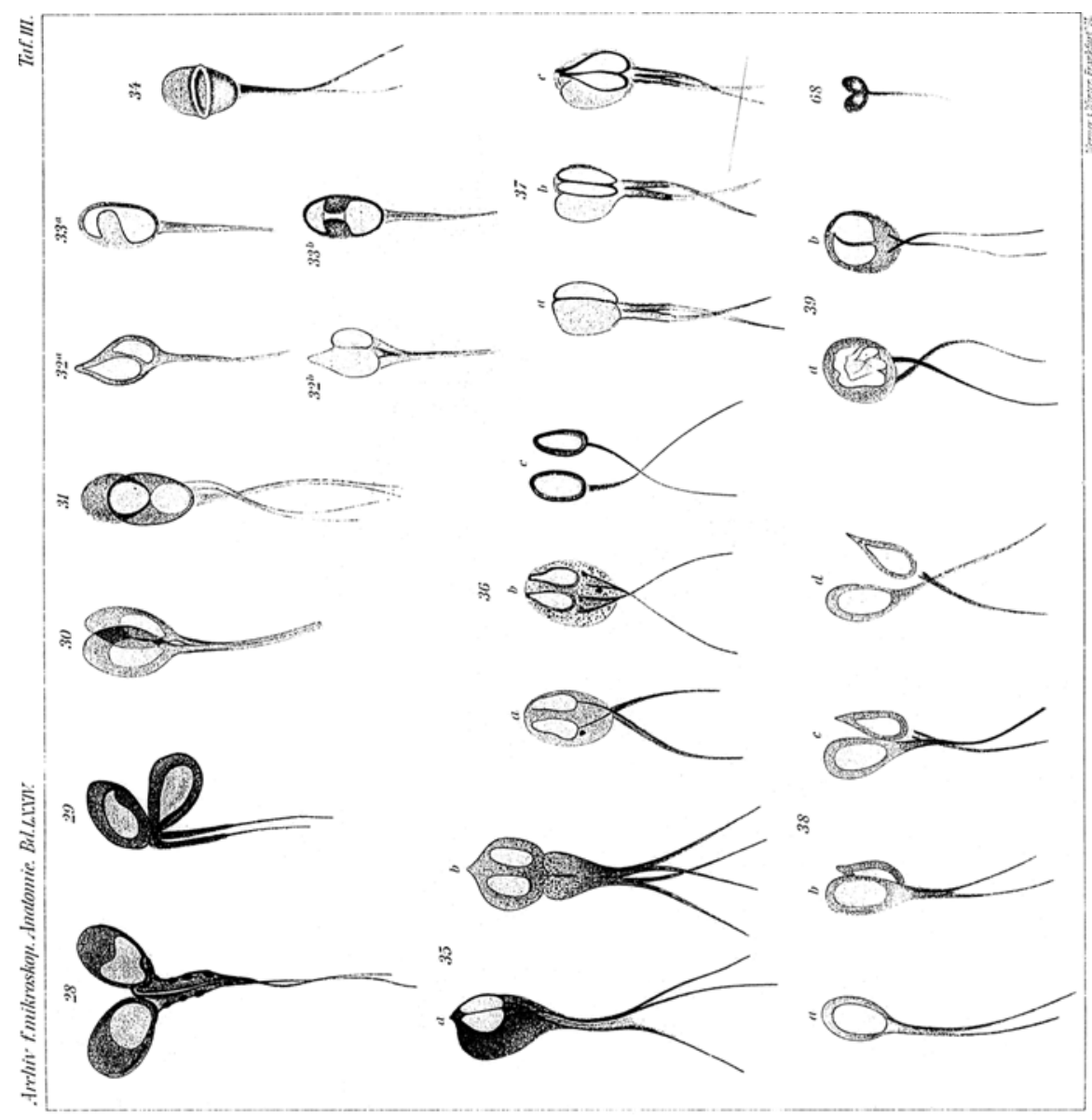




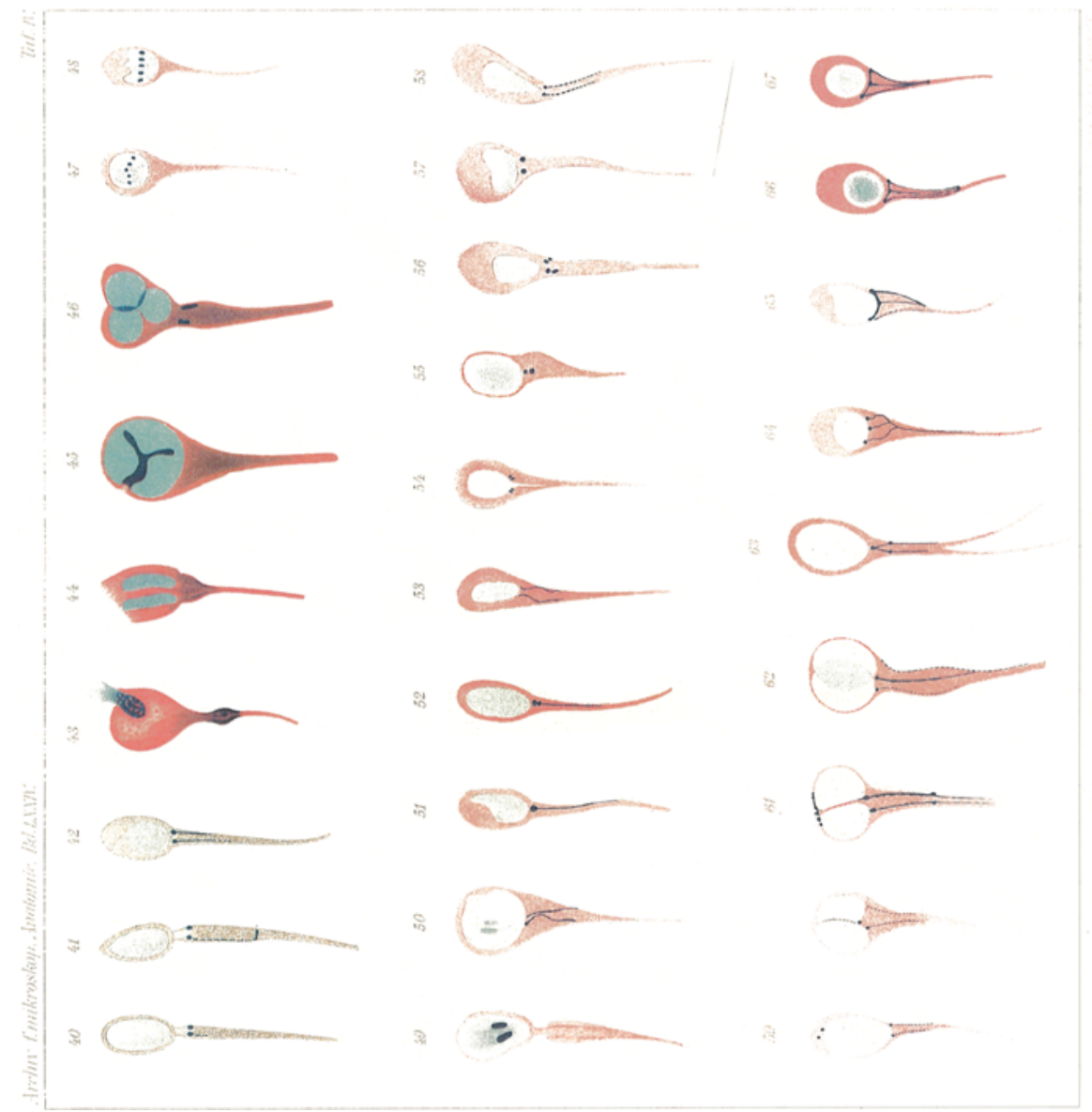

